\title{
An investigation into the crack initiation and propagation behaviour of bonded single lap joints using backface strain.
}

\author{
V. Shenoy ${ }^{\text {a }}$, I. A. Ashcroft ${ }^{a^{*}}$, G. W. Critchlow ${ }^{\text {, }}$ \\ A. D. Crocombe ${ }^{\mathrm{c}}$, M. M. Abdel Wahab . \\ ${ }^{a}$ Wolfson School of Mechanical and Manufacturing Engineering, Loughborough \\ University, LE11, 3TU, UK \\ ${ }^{b}$ Institute of Polymer Technology and Materials Engineering (IPTME), Loughborough \\ University, LE11, 3TU, UK \\ ${ }^{c}$ School of Engineering (H5), University of Surrey, Guildford, Surrey, GU2 5XH, UK
}

\begin{abstract}
In this paper, the Backface Strain (BFS) measurement technique is used to characterise fatigue damage in single lap adhesive joints subjected to constant amplitude fatigue loading. Different regions in the BFS plots are correlated with damage in the joints through microscopic characterisation of damage and cracking in partially fatigued joints and comparison with 3D finite element analysis (FEA) of various crack growth scenarios. Crack initiation domination was found at lower fatigue loads whereas crack propagation dominated at higher fatigue loads. Using the BFS and fatigue life measurement results, a simple predictive model is proposed which divides the fatigue lifetime into different regions depending upon the fatigue load. The model can be used with experimental back face strain measurements to determine the residual life of the joint in different regions of damage progression during the fatigue life.
\end{abstract}

Keywords: Fatigue; Fracture; Adhesives; Lap shear

\footnotetext{
* Corresponding author. Tel: +44 1509 227535. Fax:+44 1509 227648. Email: I.A.Ashcroft@lboro.ac.uk
} 


\section{Introduction}

Bonded joints are replacing conventional joining techniques, such as bolted or riveted joints because of their many advantages, which include; good strength-to-weight ratio, ability to join dissimilar materials and relatively uniform stress distribution. The fatigue performance of bonded joints is of great importance in many structural applications, such as those in the aircraft, automotive or marine sectors, for example. There are a number of techniques available that can be used to design bonded joints to withstand fatigue loading, however, an efficient and robust design methodology should take account of the fracture mechanisms in the joint under consideration. This involves a thorough investigation of crack initiation and propagation in the joint, preferably using in-situ monitoring of damage evolution as well as post failure analysis.

Backface strain (BFS) measurement is a technique that can be used for the in-situ monitoring of crack initiation and propagation under both static and fatigue loading. Shaw and Zhao [1] used BFS to measure the crack length in aluminium compact fracture toughness specimens and included corrections for crack closure, curvature effects and plastic zone size in their analysis. Gilbert et al. [2] used the BFS technique on diskshaped compact-tension specimens and concluded that the position of the strain gauges was not critical until the crack approached the back face. However, such an observation cannot be generalised as Crocombe et al. [3] found an optimal position for the gauges for BFS measurements on composite single lap joints (SLJs) under fatigue loading. They found that samples without fillets had a reduced fatigue life compared to those with fillets and attributed this to a reduction in the initiation phase in the former. In addition, they 
used 2D finite element analysis (FEA) to correlate BFS with crack propagation. Zhang and Shang [4] used the BFS measurement approach on steel SLJs and concluded that the crack initiated in the fillet. Graner Solana et al. [5] fatigue tested bonded single lap joints with multiple strain gauges and related the strain signals to the location of damage initiation in the joint. They also sectioned joints after various periods of fatigue testing and related the observed damage in the joints with the backface strain signal. This allowed them to draw a damage map relating damage in the joint to the backface strain.

This paper aims to provide a detailed investigation of crack initiation and propagation in SLJs using BFS measurement, and to correlate these results to damage in the samples, both experimentally and through the use of 3D FEA models with concave crack fronts, as observed experimentally. In addition, an investigation is made into different types of crack growth, namely; crack growth from one end of the overlap only, symmetric crack growth from both ends of the overlap and asymmetric crack growth. Finally, the paper aims to provide validation of the effectiveness in fatigue of a novel, environmentally friendly surface treatment for aluminium alloys that can be considered as a replacement for existing chromate containing treatments.

\subsection{Experimental}

\subsection{Sample manufacture}

British standard (BS 2001) [6] geometry was used for the SLJs in this investigation, as shown in Fig. 1(a). Initial experiments used $2.5 \mathrm{~mm}$ thick adherends, however, substrate 
failure at high cycles, prompted a change to 3mm thick adherends. Clad 7075-T6 aluminium alloy was used for the adherends and the adhesive used was FM 73M epoxy film from Cytec Engineered Materials Ltd. The adhesive film had a nominal thickness of $0.2 \mathrm{~mm}$ and was supported by a random mat carrier. Material properties for the adhesive were taken from the tensile testing of bulk adhesive specimens manufactured from multiple layers of the same adhesive film used in the joint samples. A typical stress-strain diagram for the bulk adhesive is given in Fig. 1 (b). The elastic material properties for the adhesive and adherend are given in Table 1. The aluminium alloy properties are taken from the manufacturer's data sheet.

The adherends were ultrasonically cleaned in an ultrasonic acetone bath for five minutes prior to pre-treatment using an AC DC anodisation process [7]. This treatment is proposed as an environmentally friendly alternative to current chromate containing processes. In this pre-treatment, the adherend to be treated is made one of the electrodes in an electrochemical cell. A weak mixture of phosphoric and sulphuric acid (5\%) is used as the electrolyte and titanium is used for the other electrode. An alternating current (AC) is ramped up to $15 \mathrm{~V}$ over a period of $1 \mathrm{~min}$ and then kept at this voltage for two more minutes. Thereafter, the current is changed to direct current (DC) and increased to $20 \mathrm{~V}$. The bath is kept at this voltage for a further 10 mins. The specimens are then washed with distilled water and dried using a hot air dryer. The pre-treatment results in an average oxide thickness of $1.9 \mu \mathrm{m}$ over the adherend surface, as shown in Fig. 2 (a). In this figure two layers are apparent; the bottom layer is the aluminium cladding layer and the top layer is the anodically formed oxide layer. A magnified image of the surface of the oxide 
film is shown in Fig. 2(b), where the open pored structure required for good bonding can be seen. An advantage of the AC DC process is that in addition to the open structure at the surface, produced during the AC phase, a denser structure is produced in the DC phase, which results in enhanced corrosion protection of the aluminium alloy. After the AC DC pre-treatment, a thin film of BR 127 corrosion resistant primer manufactured by Cytec Engineered Materials Ltd., was applied to the aluminium adherends. This was dried at room temperature and then cured at $120^{\circ} \mathrm{C}$ for half an hour. The adherends were returned to room temperature before bonding. The FM 73M adhesive was taken from freezer storage and brought to room temperature in a dry atmosphere before bonding. The adhesive was cured at $120^{\circ} \mathrm{C}$ for 1 hour with constant pressure applied through clips. No attempt was made to control the fillet geometry but owing to the accurate cutting of the film adhesive the natural fillets formed were fairly uniform between samples. The bonded joints were stored in a dessicator at room temperature prior to testing.

\subsection{Mechanical Testing}

All the joints were tested using an Instron 6024 servo-hydraulic testing machine. The quasi-static tests were carried out with a constant displacement rate of $0.1 \mathrm{~mm} / \mathrm{sec}$. Fatigue testing was at a load ratio of 0.1 and frequency of $5 \mathrm{~Hz}$, with a sinusoidal waveform and with various percentages of the quasi-static failure load (QSFL) taken as the maximum load in the fatigue spectrum. Tests were carried out at ambient temperature and relative humidity, which ranged from $22-25^{\circ} \mathrm{C}$ and $40-50 \%$ respectively, during the tests. 


\subsection{BFS measurement}

Prior to fatigue testing, strain gauges were bonded to the joints at the sites proposed by Crocombe et al. [3] in order to provide an in-situ monitor of damage. $3 \mathrm{~mm}$ long, $120 \Omega$, temperature compensating strain gauges made for cycling loading purposes by Vishay Instruments were used (reference: EA-13-060LZ-120). Gauge placement is shown in Fig. 3(a). The standard process described in the M-bond adhesive strain gauge bonding kit, provided by Vishay Instruments, was used to bond the strain gauges onto the back-faces of the SLJs. The lead wires were soldered onto insulator bases first then the wires from the bases were connected to the data logging device. Connecting the strain gauges' lead wires to the bases first avoids loading on the lead wires during fatigue loading. A photograph of the strain gauges bonded onto the SLJs is shown in Fig. 3 (b). A strain gauge signal conditioner, the microANALOG 2, manufactured by FYLDE Plc., was used to condition the strain output signal and the strain gauge signal was computer logged throughout the fatigue testing.

It can be seen from Fig. 3(a) that one of the strain gauges (SG1) is bonded to the adherend attached to the load actuator and the other gauge (SG2) is bonded to the adherend attached to the load cell during testing. This is potentially significant as it was observed that different lateral movement was seen at the two end of the joint during testing. This is illustrated in Fig. 4 which shows the results from dial gauge reading placed at various locations around a joint as it was loaded. The angular rotation ' $\theta$ ' in the joint is calculated using eqn. (1): 


$$
\theta=(100-X) / S
$$

Where, $X$ is the distance from the end of either of the substrates, $S$ is the dial gauge measurements in mm. Current, maximum and minimum strains were measured during loading; however, only the maximum are used in the figures.

\subsection{Optical microscopy}

To monitor damage, or crack, progression, samples were fatigue tested for a certain number of cycles, then removed from the test machine before complete failure and sectioned and mounted in resin. The joints were sectioned at the three locations, $\mathrm{L}_{-} \mathrm{L}_{1}, \mathrm{C}-$ $\mathrm{C}_{1}$ and $\mathrm{R}-\mathrm{R}_{1}$ shown in Fig. 5(a) where sections L-L1 and R-R1 are 6-8mm from the edge of the sample. The mounted sections were progressively polished to a 1 micron finish. An example of mounted and polished sections can be seen in Fig. 5(b). The polished sections were examined using an Olympus BX60M microscope. The damage in the adhesive was highlighted by using dark focus filters.

\subsection{Results}

\subsection{Mechanical test results}

An average QSFL of $11.95 \mathrm{kN}$ was found for the five samples tested, with a standard deviation (SD) of $0.31 \mathrm{kN}$. A typical load vs. displacement curve for the test is given in Fig. 6 (a). This shows an approximately linear global response of the joint to loading. No plastic deformation was noted in the adherends after testing, although signs of localised plasticity could be seen in the adhesive fracture surfaces. The fracture surfaces exhibited predominantly cohesive failure in the adhesive, as shown in Fig. 6(b), which 
demonstrates the effectiveness of the environmentally friendly AC DC surface pretreatment. The fatigue test data for the samples with $2.5 \mathrm{~mm}$ thick adherends are presented in Fig. 7 (a). It can be seen that there is a linear increase in the log of cycles to failure with decrease in maximum fatigue load. At fatigue loads lower than $6.5 \mathrm{kN}$, aluminium adherend failure was seen before failure in the adhesive in many joints. The location of adherend failure was $2-5 \mathrm{~mm}$ outside the overlap region. In order to obtain failure in the adhesive at high cycles an increased adherend thickness of $3 \mathrm{~mm}$ was used. The fatigue results from these experiments are shown in Fig. 7(b). It can be seen in this figure that similar results are seen for both adherend thicknesses.

\subsection{Damage evolution at higher fatigue loads}

Different fatigue behaviour was seen at high and low fatigue loads and to aid discussion of the results in this paper, high fatigue loads are nominally defined as loads greater than $50 \%$ of the QSFL. In Fig. 8, BFS is plotted against number of fatigue cycles for a sample fatigue tested with a maximum fatigue load of $63 \%$ of the QSFL $(7.5 \mathrm{kN})$. SG1 and SG2 denote the maximum strains during the fatigue testing for the two strain gauges illustrated in Fig. 3(a). The difference in initial strain between SG1 and SG2 is most likely due to unequal sized fillets at the ends of the overlap, as discussed further in section 3.4. Three regions can be seen in this figure; Region I, in which strain increase is decelerating (approximately 500 cycles), Region II, in which strain increases approximately linearly (approximately 6000 cycles) and region III, in which strain growth accelerates (approximately 4000 cycles). In order to understand the BFS results it is important to note that there are three possible crack growth scenarios when testing SLJs. These are; a) crack growing from only one end of the overlap (type I crack growth), b) approximately 
symmetric crack growth from both ends of the overlap (type II crack growth) and c) significantly asymmetric crack growth (type III crack growth). These crack growth scenarios are shown schematically in Figs. 9(a), (b) and (c).

In order to correlate the BFS plots with damage in the samples, a series of experiments were carried out in which joints were tested for a certain number of fatigue cycles and then examined for damage both externally and internally, through sectioning. Firstly, a joint was tested at 63\% of the QSFL for 200 cycles. Fig. 10 (a) shows the BFS plot from this test and a small increase in the BFS can be seen for both gauges. No external damage was seen in this sample. Fig. 10(b) shows an optical micrograph of a polished section from the middle of the joint at the SG1 end of the overlap (section C-C1 in Fig. 5(a)). Filters can be used to highlight micro-damage in these sections and in Fig. 10(b) it can be seen that although a macro-crack has not formed, there is damage in the fillet adjacent to the embedded corner of the adherend. It is significant that this is in an area of high predicted stress.

Further joints were fatigue tested at the same load, but for different numbers of cycles. Fig. 11(a) shows BFS plotted against number of fatigue cycles for a joint tested for 500 cycles. SG1 exhibits Regions I and II from Fig. 8, whereas SG2 shows a small increase in strain, similar to that seen in Fig. 10(a). Again, no external cracking was observed, however, Fig. 11(b) shows that a crack of approximately $0.4 \mathrm{~mm}$ in length formed at the centre of the joint at the SG1 end of the overlap. The same section at the other (SG2) end of the overlap showed no cracking but a region of damage similar to that in Fig. 10(b) 
was seen. Fig. 12(a) shows the BFS graph for a joint tested for 2500 cycles, with both SG1 and SG2 showing Regions I and II from Fig. 8. Again, no external cracking could be seen, however, sub-surface cracking could be seen in the fillet area, owing to the semitransparent nature of the adhesive, as shown in Fig. 12(b). In this case, sectioning showed that there was crack growth in the middle of the joint at both ends of the overlap. The fillet area in the middle of the joint at the SG1 end of the overlap is shown in Fig. 12(c). It can be seen that the crack has grown from the region of the embedded adherend corner, both along the overlap and through the fillet, although it has not quite reached the fillet surface. Similar crack growth was seen in the centre section at the SG2 end of the overlap, however, the crack seen at the SG1 end was approximately 4 times larger than that at the SG2 end. Fig. 13(a) shows the BFS plot of a sample tested for 5000 cycles. Both gauges exhibit Regions I and II, with the larger strain changes seen in SG1. Accordingly, larger cracks were seen at the SG1 end, the crack length ratio for SG1 to SG2 being approximately 10:1. Figure 13(b) shows the central section at the SG1 end of the overlap and it can be seen that a well developed crack has grown along the bondline. The crack has broken through to the fillet surface at the SG1 end but external signs of cracking along the bondline were still not observed.

Table 2 shows a summary of the crack and damage lengths measured in the sectioning experiments. It can be seen that cracking is far more developed in the centre sections than in the edge sections. Hence, for the joints tested at $63 \%$ of QSFL, the total fatigue life can be divided into three regions. Firstly, a region of initial damage formation in the fillet, secondly, a region of asymmetric crack and damage progression from both ends of 
the overlap, in which damage is concentrated in the centre of the joint. Thirdly there is a region of rapid crack growth prior to final failure of the joint. It should be noted, however, that the rapid crack growth takes place only until a certain crack length at which point the joint is sufficiently weakened that there is a quasi-static type of crack growth. Regions I, II and III take up approximately $2-5 \%, 50-70 \%$ and $20-30 \%$ of the total fatigue life respectively for the samples tested at $63 \%$ of QSFL.

Joints were also tested with a maximum fatigue load which was 54\% of the QSFL. Similar regions of crack initiation and propagation were also found at this load. Fig.14 (a) shows a comparison of the BFS plots for samples tested at 54\% and 63\% of QSFL. Unsurprisingly the cycles to failure is significantly lower and the back face strains higher for the sample tested at the higher fatigue load. In order to provide a better comparison of the BFS plots, Fig. 14(b) shows the same data in which the BFS and number of fatigue cycles are normalised. It can be seen that both plots exhibit Regions I, II and III.

\subsection{Damage evolution at lower fatigue loads}

Lower fatigue loads are defined in this paper when the maximum fatigue load is less than $50 \%$ of the QSFL. Fig.15 shows the BFS plot for a sample tested at $40 \%$ of QSFL. It can be seen that there is very little change in the BFS until a rapid increase is seen in the final stage of its fatigue life. As with the higher fatigue loads, additional experiments were conducted wherein partially tested joints were sectioned to inspect for damage or crack growth. Fig. 16(a) shows the BFS plot for a specimen tested for 50,000 cycles. A small increase in the BFS is seen, which corresponds to the evolution of micro-damage, as shown in Fig. 16 (b). However, there was no sign of macro-cracking in the sample, either 
internally or externally. In another test at $40 \%$ of QSFL the test was stopped just after a sharp increase in the BFS was seen, as shown in Fig. 17 (a). On sectioning, a crack was seen at the central section of the joint at both ends. The larger crack was seen at the SG1 end of the overlap and this is shown in Fig. 17(b). Damage was also observed in other sections, as illustrated by the damage seen in the L-L1 section shown in Fig. 17 (c).

A summary of the crack and damage measurements from sectioning samples tested at $40 \%$ of QSFL can be seen in Table 3. If the total fatigue lifetime is taken as approximately 100,000 cycles then the time spent in crack initiation is approximately $85 \%$ of the total fatigue life at $40 \%$ of QSFL.

\subsection{Comparison of FEA and experimental results}

In order to aid interpretation of the experimental BFS results, a 3D finite element analysis (FEA) was conducted using MSc Marc Mentat 2001r3 finite element software. Eight noded hexahedral elements were used with geometric and material non-linearity. A von Mises plasticity surface was used for the adhesive with a yield stress value of 40MPa [14] This is a good enough approximation in this case as the simulations were only used to analyse the backface strains on the surface of the aluminium adherends. The SLJ was modeled with fillets of different size at the two ends of the overlap, as seen experimentally, except for type II crack growth, where symmetry was assumed. The fillet shapes were based on measurements from the joints used in the experiments. A concave crack front was used in the models, as shown schematically in Fig. 18(a). The shape of the crack was based on the experimental crack measurements, with the crack length at the centre higher than that at the edges. A 2D view of the mesh can be seen in Fig. 18(b) that highlights the asymmetric modelling of the fillets. Fig. 18(c) shows a 3D 
view of an uncracked joint and Fig. 18(d) shows the deformation after loading of a cracked joint, with the joint sectioned at the centre to emphasise the crack. The crack length is greatest at the centre of the joint and has not grown fully across the sample width at this point. Different FE models were used for each crack growth increment with the crack shape based on experimental observations.

FEA analyses were carried out simulating type I, II and III crack growth. Fig. 19(a) shows FEA simulated BFS plotted as a function of maximum crack length for type I crack growth. It can be seen that there is a difference in the initial BFS value for SG1 and SG2, which can be attributed to the different sized fillets, with the smaller fillet corresponding to the larger initial strain value. The crack was grown from the SG1 end of the overlap (as this is the end with the greatest initial strain) and it can be seen that the SG1 signal increases non-uniformly with crack length, whereas, the SG2 signal remains relatively constant. In SG1 there is an initial increase in the strain, followed by a gentle increase in the strain between 0.2 and $0.8 \mathrm{~mm}$, after which there is a sharp increase in the strain gradient. This type of behaviour was seen in a number of the tested samples, e.g. Figs. 8 and 11, and is indicative of initial crack growth predominantly at the end of the overlap showing the increase in strain. Moreover, in agreement with the FEA, it was seen experimentally that the crack tended to start at the end with the smaller fillet. Fig. 19 (b) shows a FEA simulated BFS plot for type II crack growth. Crack length in this case is the sum of the cracks lengths at the centre of the joint from both ends of the overlap. The BFS increases in both gauges as the crack length increases, which can also be viewed in the experiments where cracking is from both sides, e.g. Fig. 12. However, it 
can be seen there is a small difference between SG1 and SG2. This is due to the different amount of rotation present in the two substrates, as shown experimentally in Fig. 4. The loaded (SG1) end shows a greater degree of rotation than the fixed (SG2) end and this corresponds to a greater initial backface strain. It can be seen by comparing Figs. 19(a) and 19(b), however, that the initial strain difference caused by the asymmetric fillets is greater than that caused by the asymmetric loading. Hence it can be said that sample geometry has a greater effect in determining the site for initial crack growth than orientation in the test machine.

Fig. 19(c) shows the FEA simulated BFS plots for type III crack growth as a function of the total crack length in the middle of the joint. The crack lengths used in this FEA analysis were based on the experimentally measured crack lengths and are shown in Table 4. This figure is similar to many of the experimentally observed BFS plot, indicating that type III is the most common form of crack growth, as further confirmed from the experimental crack length measurements. Figure 20 compares an FEA BFS plot for type III crack growth with a maximum fatigue load of $63 \%$ of QSFL and a corresponding experimental BFS plot. It can be seen that there is generally a very good agreement between the experimental and FEA plots. The difference in the two plots can be attributed to such factors as neglecting the effect of the experimentally observed damage zones and differences between the actual and simulated crack geometries.

\subsection{Damage progression model}

Using both BFS measurement and fatigue testing results, a simple graphical model is proposed which, can be used to deduce the residual life of the joint in the different regions of crack progression. In Fig. 21, the normalised BFS (with respect to the 
maximum BFS measured) and the maximum fatigue load as a percentage of QSFL are plotted against the logarithmic number of fatigue cycles. This figure shows that the development of BFS is dependent on the fatigue load. This can be considered further by relating the BFS with the experimental crack and damage measurements and the $3 \mathrm{D}$ simulations to create a model of damage progression, as shown in Fig. 22. The region below the failure curve (L-N curve) can be divided into three parts: region 'FCG', a region of fast crack growth from both ends of the overlap; region 'SCG', a region of slow crack growth, where the crack growth rate from one end is slower than the other end and region ' $\mathrm{CI}$ ', in which damage accumulates prior to macro-crack formation. It can be seen that in the model the crack initiation region dominates at low loads but diminishes as the fatigue load reaches the quasi-static failure load. The region of slow crack growth is most significant at intermediate loads, whereas fast crack growth dominates at high fatigue loads. It can be seen that the regions of initiation, slow crack growth and fast crack growth domination can be identified in the corresponding BFS plots. Hence the BFS plot can be used to monitor the type of failure of the joint as well as to monitor damage progression and in particular to identify the onset of the damaging fast crack growth region which quickly leads to complete failure. Moreover, a calibrated BFS signal can be used together with the L-N graph to predict the remaining life of a joint after a period of testing.

\section{Conclusions}

It has been shown that fatigue failure in bonded joints goes through a series of stages including an initiation period, a slow fatigue crack growth period, a fast fatigue crack growth period and a final rapid quasi-static type fracture. Moreover, it is seen that the 
period of time the joint spends in each of these regions of crack growth is dependent on the fatigue load, with initiation dominating at low loads and fast fracture dominating at high loads. It is shown that backface strain can be used to differentiate between the different types of behaviour and for in-situ monitoring of damage progression in the joints. A model is proposed that links the backface strain to the progression of damage in joints at different loads. This can be used to monitor the type of damage progression and predict residual fatigue life.

\section{References}

[1] Shaw WJD and Zhao W. ASTM J. Test. Eval., 1994; 22(6):512-516.

[2] Gilbert CJ, McNaney JM, Dauskardt RH and Ritchie RO. ASTM J. Test. Eval. 1994; 22(1):117-120.

[3] Crocombe AD, Ong CY, Chan CM, Abdel Wahab MM and Ashcroft IA. J. Adhes. 2002; 78:745-776.

[4] Zhang Z and Shang JK. J. Adhes. 1995; 49:23-36.

[5] Graner Solana A, Crocombe AD, Abdel Wahab MM and Ashcroft IA. J. Adhesion Sci. Technol. 2007; 21:1343-1357.

[6] British Standard BS ISO (4587:2003).

[7] Critchlow G, Ashcroft I, Cartwright T and Bahrani D, Anodising aluminium alloy, UK patent no. GB 3421959A

[8] Jumbo F. PhD Thesis, Loughborough University. 2007: 208-210. 
Table 1 Elastic material properties.

\begin{tabular}{ccc}
\hline & Aluminium (7075-T6) & Adhesive (FM73M) \\
\hline $\mathrm{E}(\mathrm{GPa})$ & 70.0 & 2.00 \\
$v$ & 0.33 & 0.38 \\
\hline
\end{tabular}

Table 2 Damage and crack length measurements from sections of samples tested at $63 \%$ of QSFL (crack lengths shown in bold letters).

\begin{tabular}{|c|c|c|c|c|c|c|c|}
\hline \multicolumn{3}{|c|}{$\begin{array}{c}\text { Damage/crack } \\
\text { length from SG1 } \\
\text { side }[\mathrm{mm}]\end{array}$} & \multicolumn{3}{|c|}{$\begin{array}{c}\text { Damage / crack } \\
\text { length from SG2 side } \\
{[\mathrm{mm}]}\end{array}$} & \multirow[t]{2}{*}{$\begin{array}{l}\text { Total crack } \\
\text { length } \\
\text { [mm] }\end{array}$} & \multirow[t]{2}{*}{$\begin{array}{c}\text { Number of } \\
\text { fatigue cycles }\end{array}$} \\
\hline $\mathrm{L}-\mathrm{L}_{1}$ & $\mathrm{C}-\mathrm{C}_{1}$ & $\mathrm{R}-\mathrm{R}_{1}$ & L-L $\mathrm{L}_{1}$ & C- $\mathrm{C}_{1}$ & $\mathrm{R}-\mathrm{R}_{1}$ & & \\
\hline 0.59 & 0.38 & 0.03 & 0.13 & 0.24 & 0 & 0.38 & 500 \\
\hline 0.1 & 0.5 & 0.05 & 0.02 & 0.08 & 0.24 & 0.75 & 2500 \\
\hline 0.1 & 1.5 & 0.05 & 0.1 & 0.09 & 0.01 & 1.75 & 5000 \\
\hline
\end{tabular}

Table 3 Damage and crack length measurements from sections of samples tested at $40 \%$ of QSFL (crack lengths shown in bold letters).

\begin{tabular}{cccccccc}
\hline $\begin{array}{c}\text { Damage/crack length } \\
\text { from SG1 side [mm] }\end{array}$ & $\begin{array}{c}\text { Damage / crack } \\
\text { length from SG2 side } \\
{[\mathrm{mm}]}\end{array}$ & $\begin{array}{c}\text { Total } \\
\text { crack } \\
\text { length } \\
{[\mathrm{mm}]}\end{array}$ & $\begin{array}{c}\text { Number of } \\
\text { fatigue cycles }\end{array}$ \\
\cline { 1 - 5 }${\mathrm{L}-\mathrm{L}_{1}}$ & $\mathrm{C}_{-} \mathrm{C}_{1}$ & $\mathrm{R}-\mathrm{R}_{1}$ & $\mathrm{~L}-\mathrm{L}_{1}$ & $\mathrm{C}_{-} \mathrm{C}_{1}$ & $\mathrm{R}_{\mathrm{n}} \mathrm{R}_{1}$ & & \\
\hline 0.32 & 0.72 & 0 & 0 & 0.07 & 0 & $\mathbf{0}$ & 50000 \\
0.21 & $\mathbf{0 . 4}$ & 0.05 & $\mathbf{0 . 0 1}$ & $\mathbf{0 . 0 5}$ & 0 & $\mathbf{0 . 4 5}$ & 110000 \\
\hline
\end{tabular}

Table 4 Asymmetric crack lengths used in FE analysis of type III fracture

\begin{tabular}{llll}
\hline $\begin{array}{l}\text { Crack length from } \\
\text { loaded end }[\mathrm{mm}]\end{array}$ & $\begin{array}{l}\text { Crack length from } \\
\text { fixed end }[\mathrm{mm}]\end{array}$ & $\begin{array}{l}\text { Total crack } \\
\text { length }[\mathrm{mm}]\end{array}$ & $\begin{array}{l}\text { No. } \\
\text { cycles }\end{array}$ \\
\hline 0.14 & 0.14 & 0.28 & 50 \\
0.16 & 0.14 & 0.3 & 1000 \\
0.62 & 0.14 & 0.76 & 3000 \\
1.65 & 0.14 & 1.79 & 8000 \\
1.65 & 0.73 & 2.38 & 10000 \\
\hline
\end{tabular}




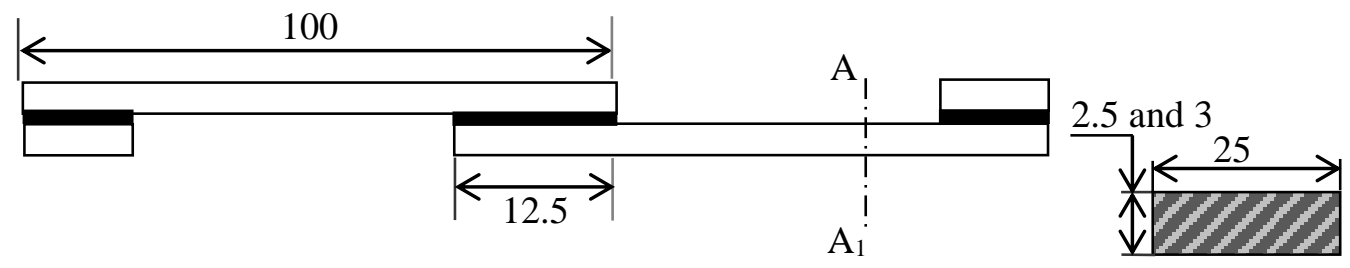

Section A-A

(a)

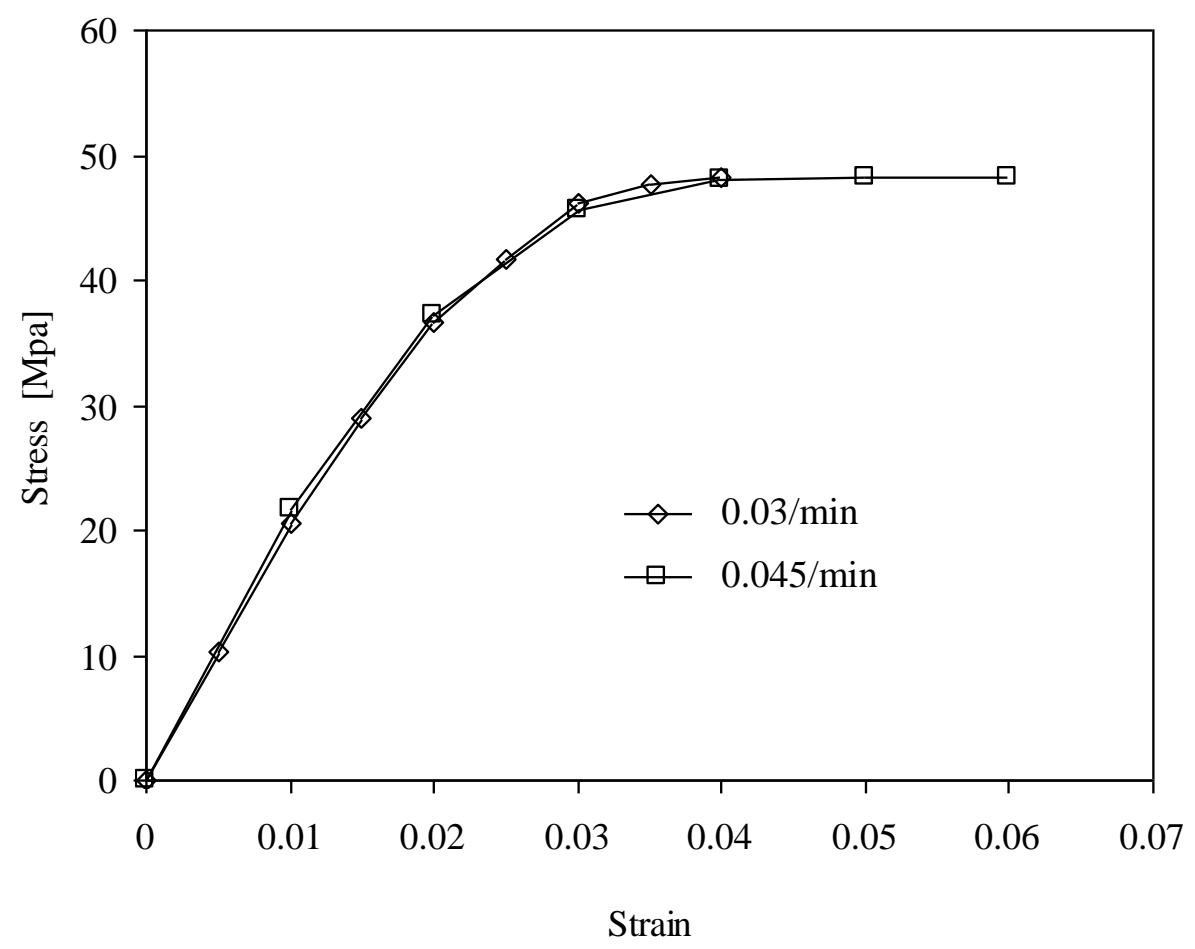

Fig. 1. (a) SLJ geometry (dimensions in $\mathrm{mm}$ ) (b) Stress-strain diagram for bulk FM73 adhesive at different strain rates. 

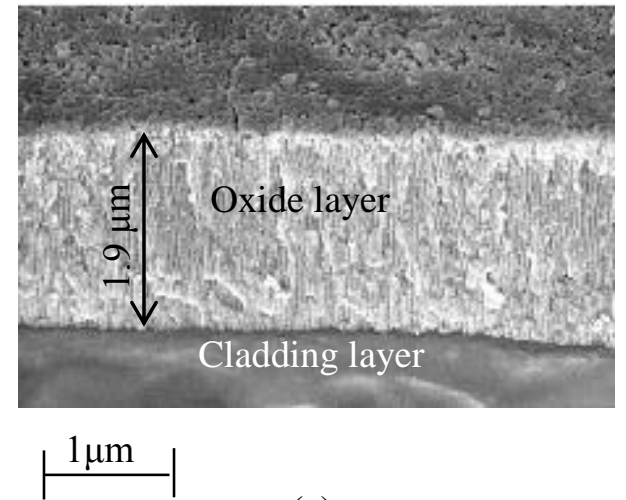

(a)
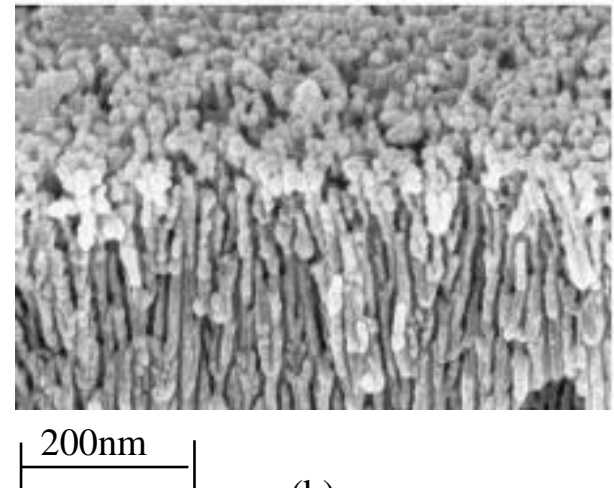

(b)

Fig. 2. Electron micrographs showing: (a) aluminium oxide layer formed during the AC DC pre-treatment and (b) magnified image of the porous surface structure. 


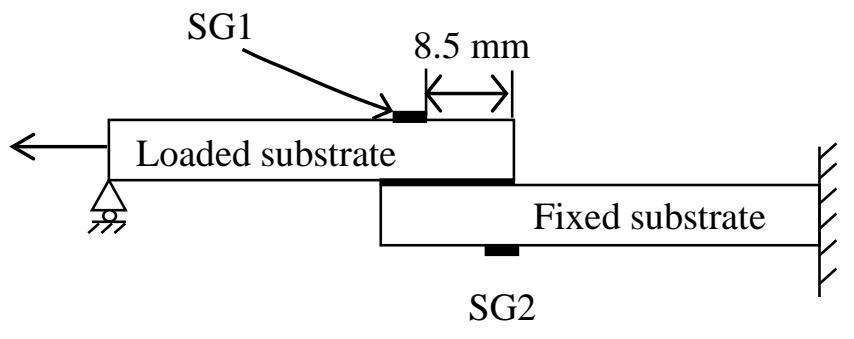

(a)

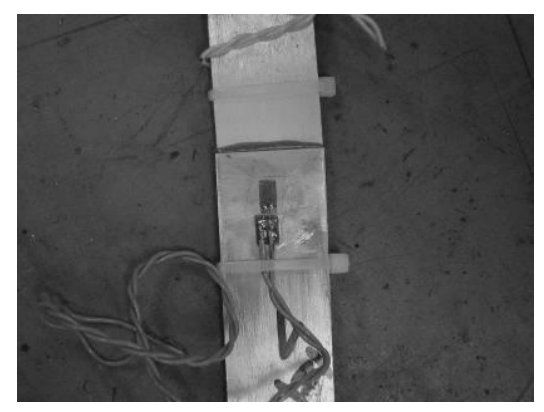

(b)

Fig. 3. (a) Strain gauge locations. (b) Strain gauges mounted on the SLJ.
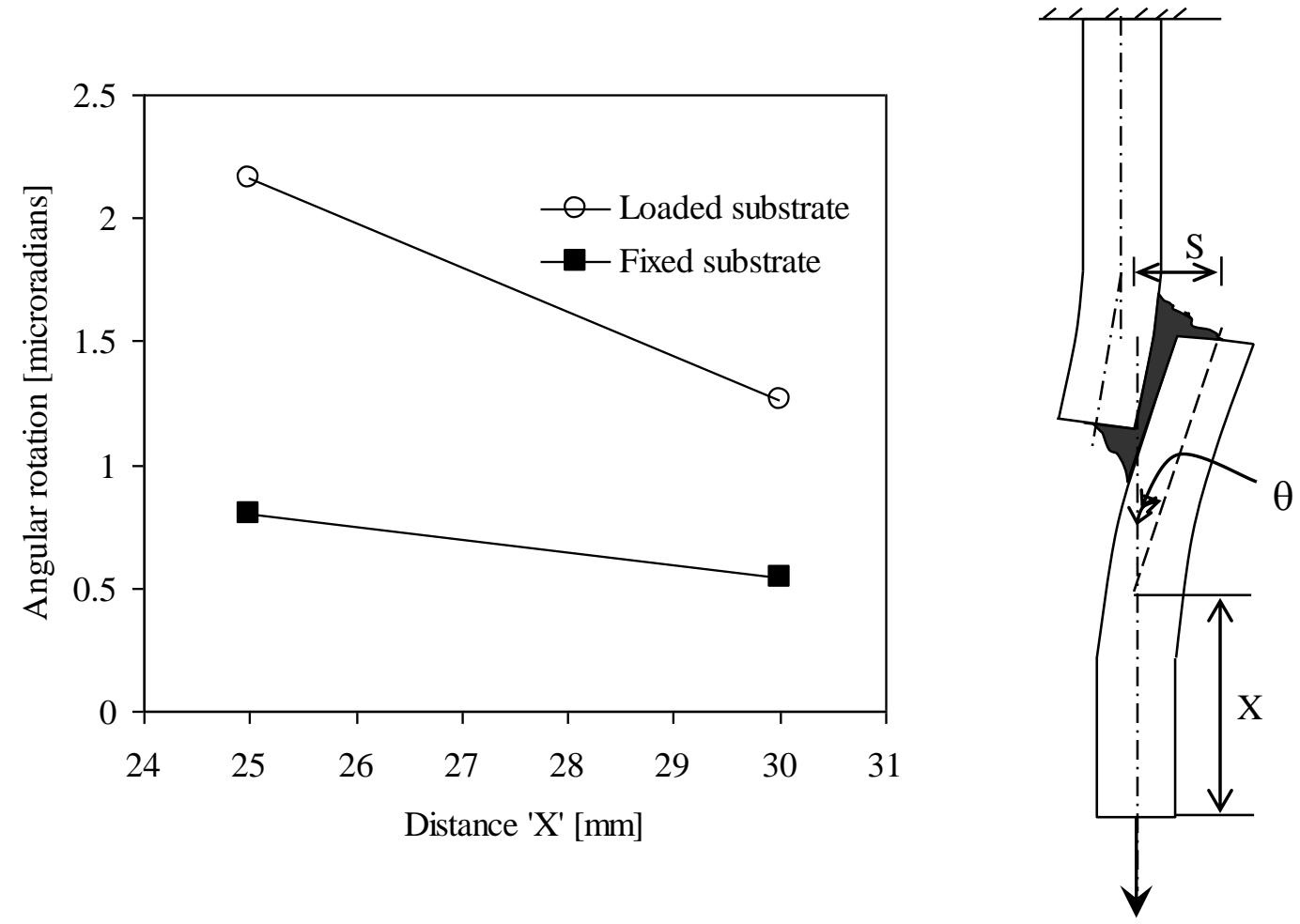

Fig. 4. Variation in bending of sample during loading. 


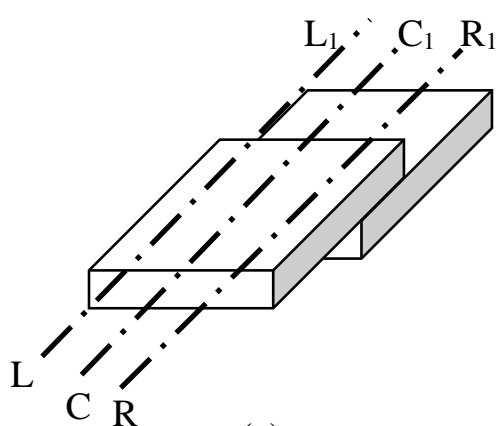

(a)

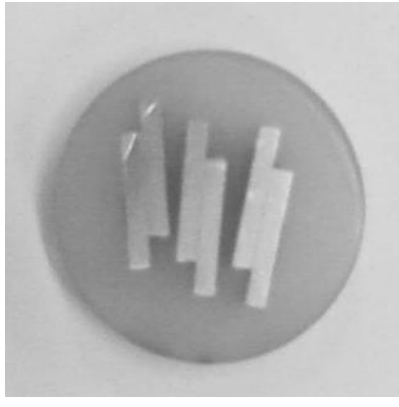

(b)

Fig. 5. (a) Section locations on the joint. (b) Mounted and polished sectioned joints. 


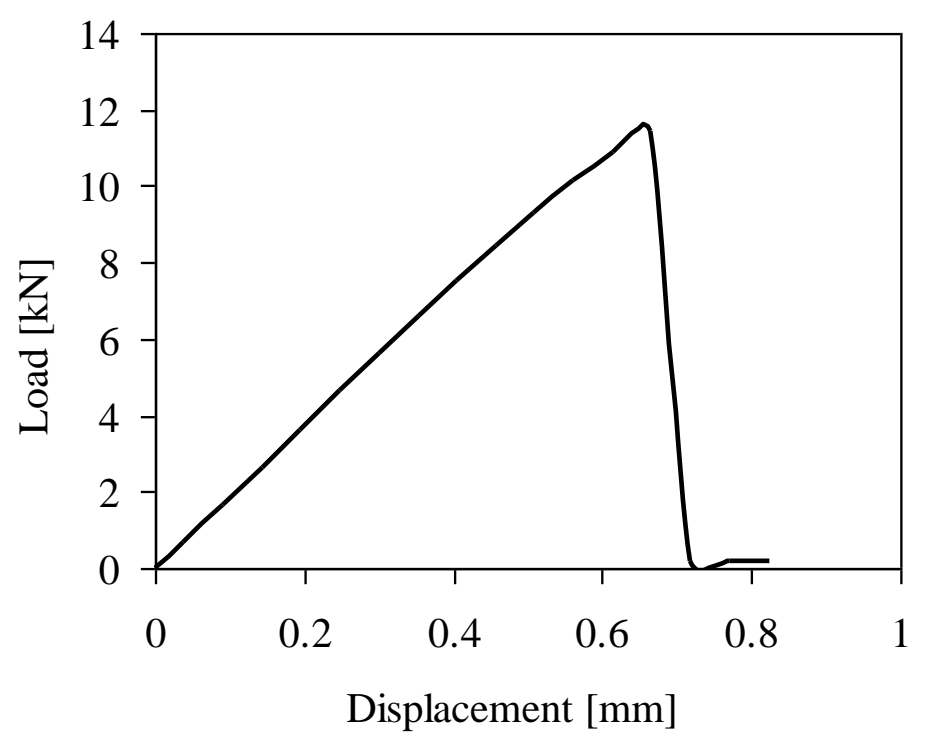

(a)

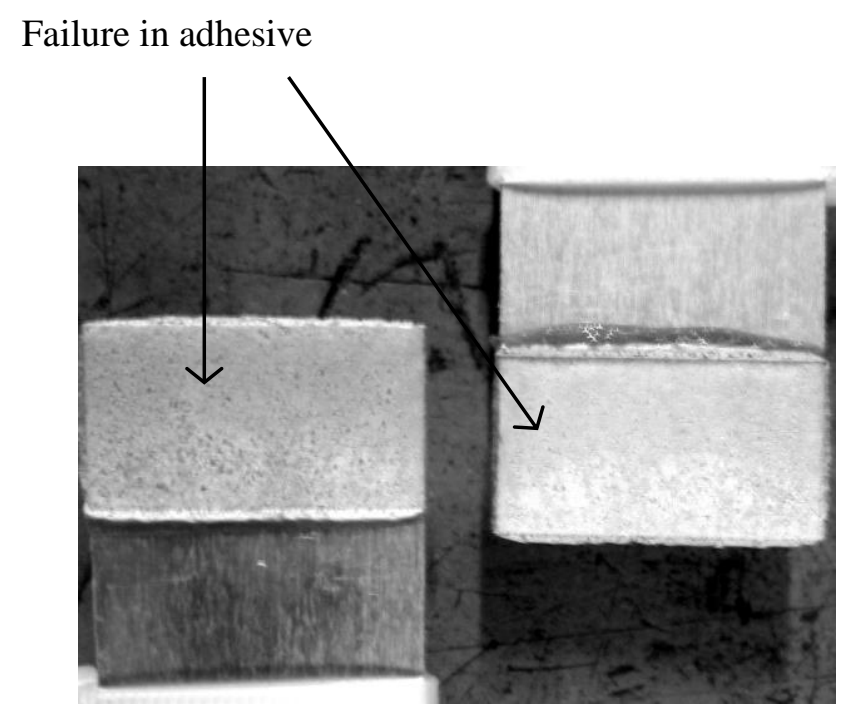

(b)

Fig. 7. Quasi-static loading: (a) typical load displacement plot; (b) fracture surface showing cohesive failure. 


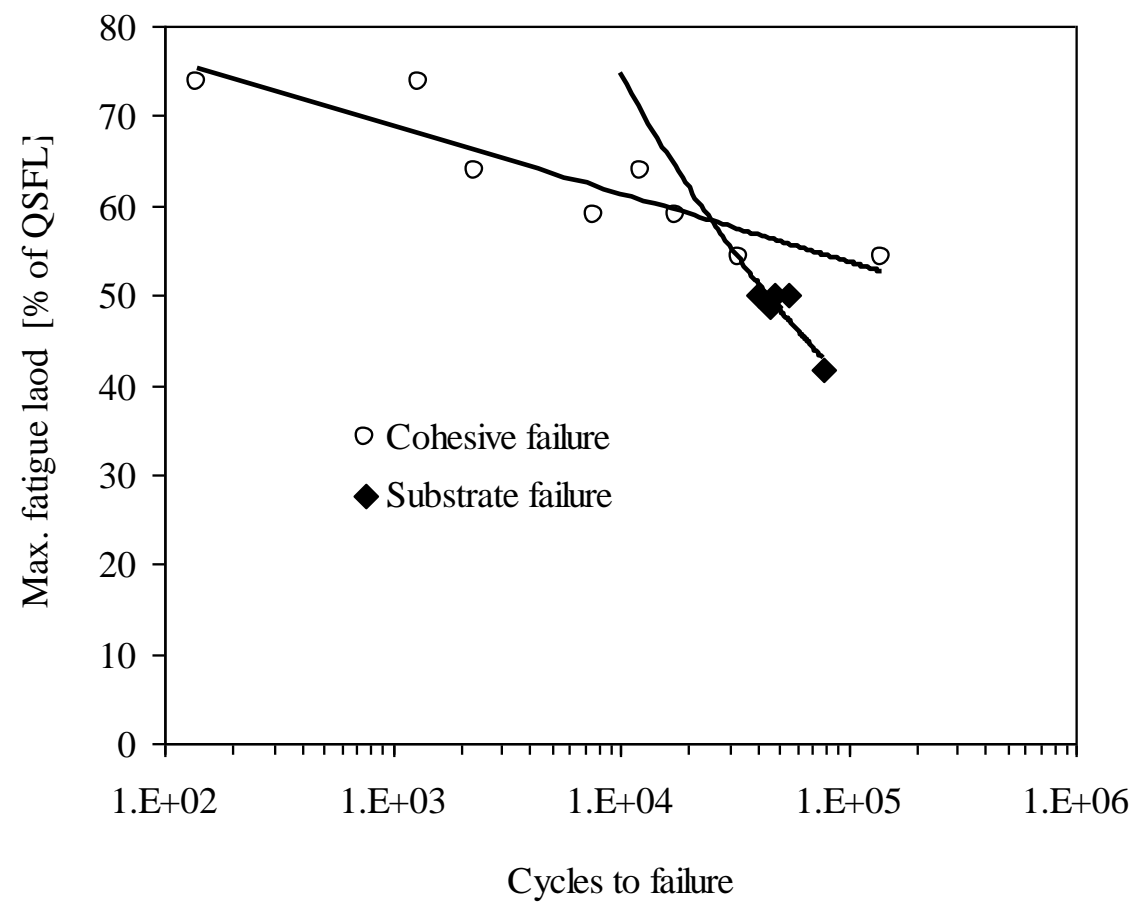

(a)

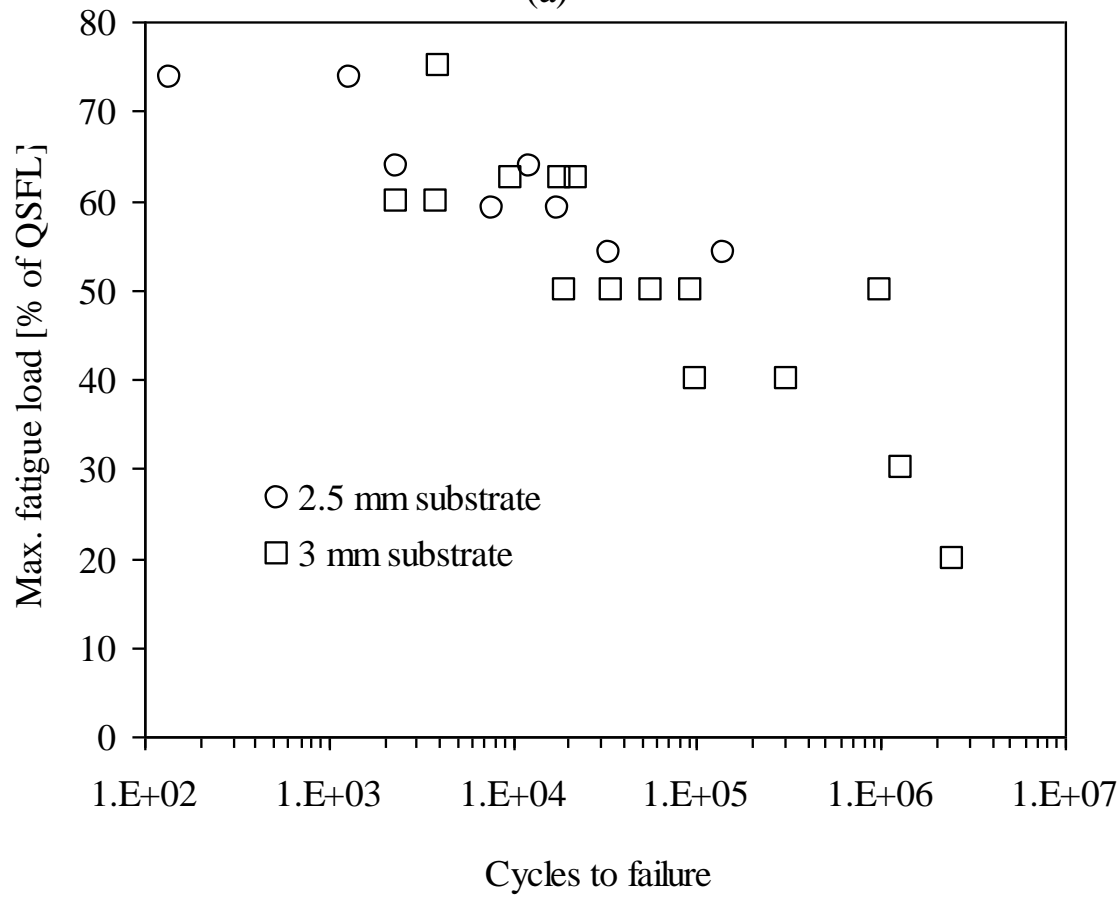

(b)

Fig. 7. (a) L-N curves with $2.5 \mathrm{~mm}$ thick adherends. (b) L-N curves comparing fatigue lives for 2.5 and $3 \mathrm{~mm}$ adherend thicknesses. 


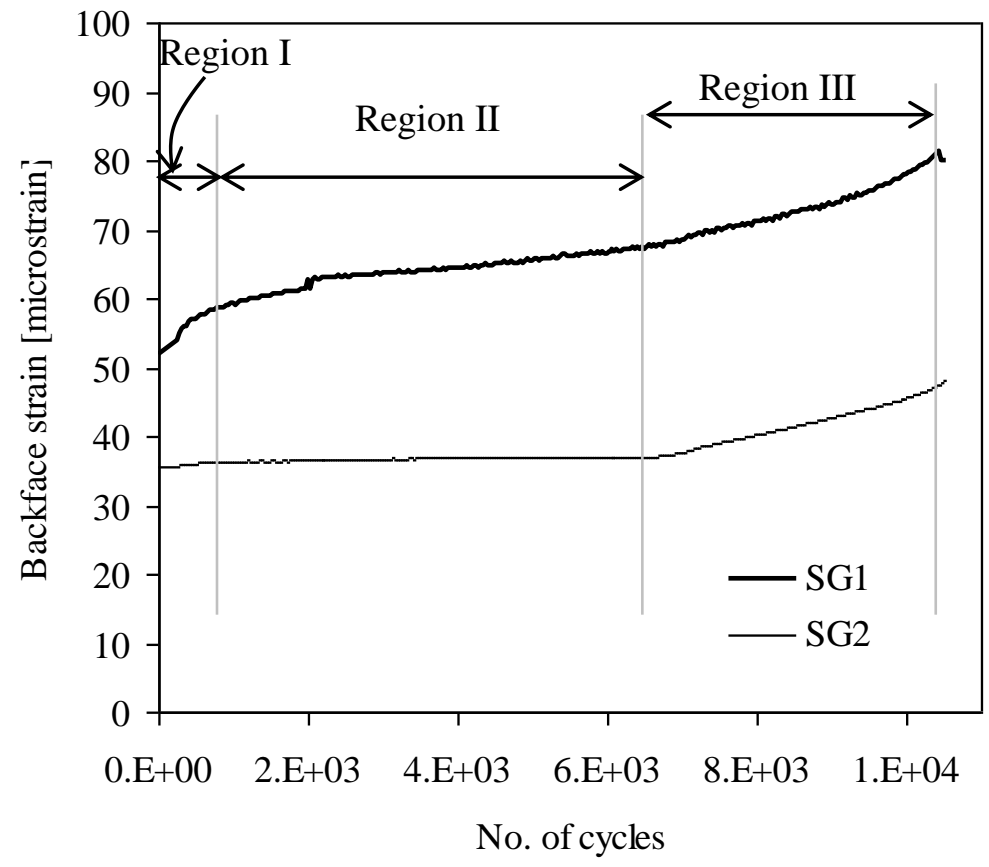

Fig. 8. BFS plot for sample tested to failure (load 63\% of QSFL).
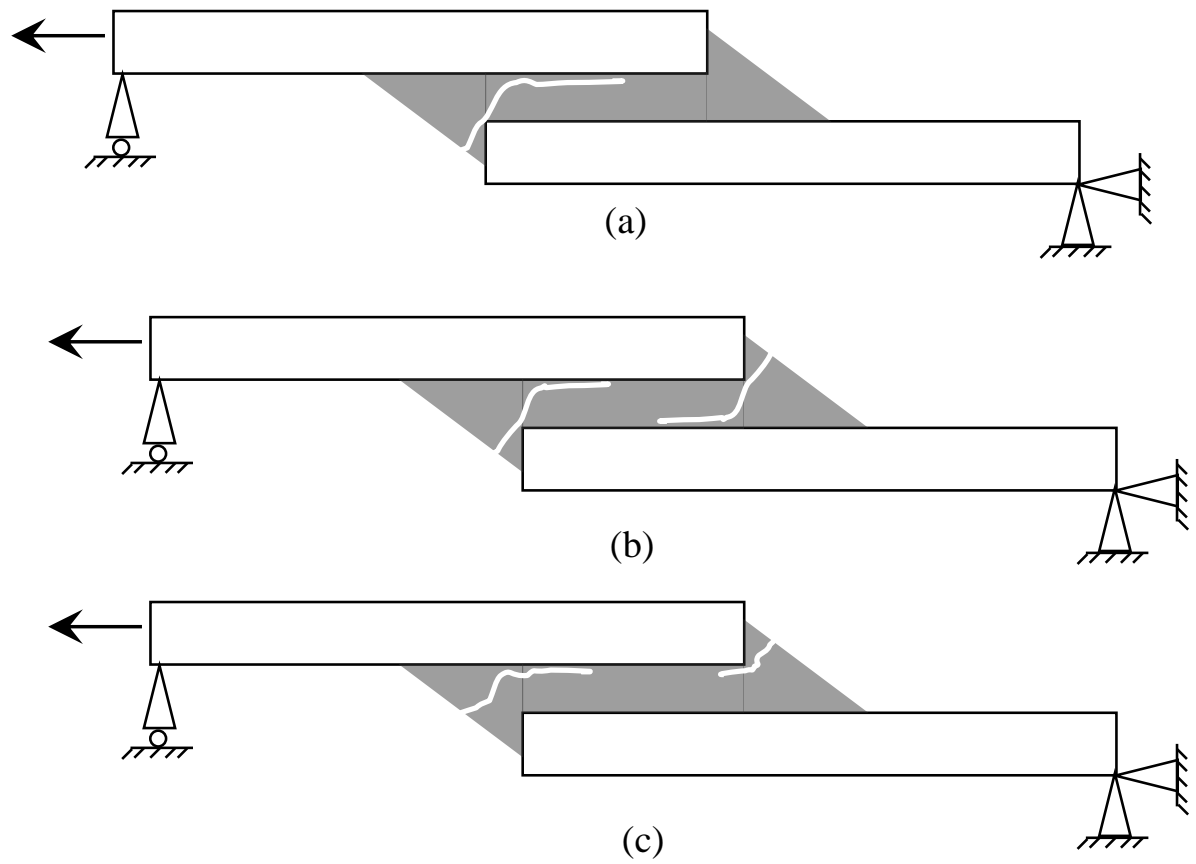

Fig. 9. (a) Type I crack growth - crack growing from only one side, (b) type II crack growth symmetric crack growth, (c) type III crack growth - asymmetric crack growth. 


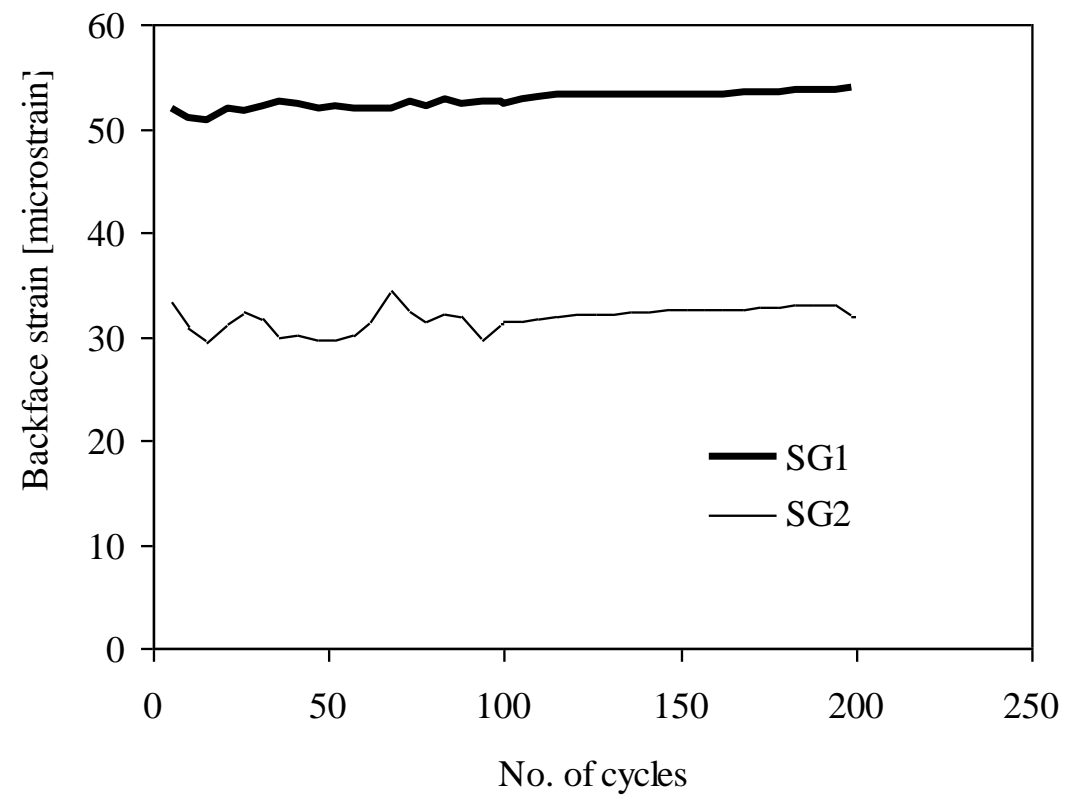

(a)

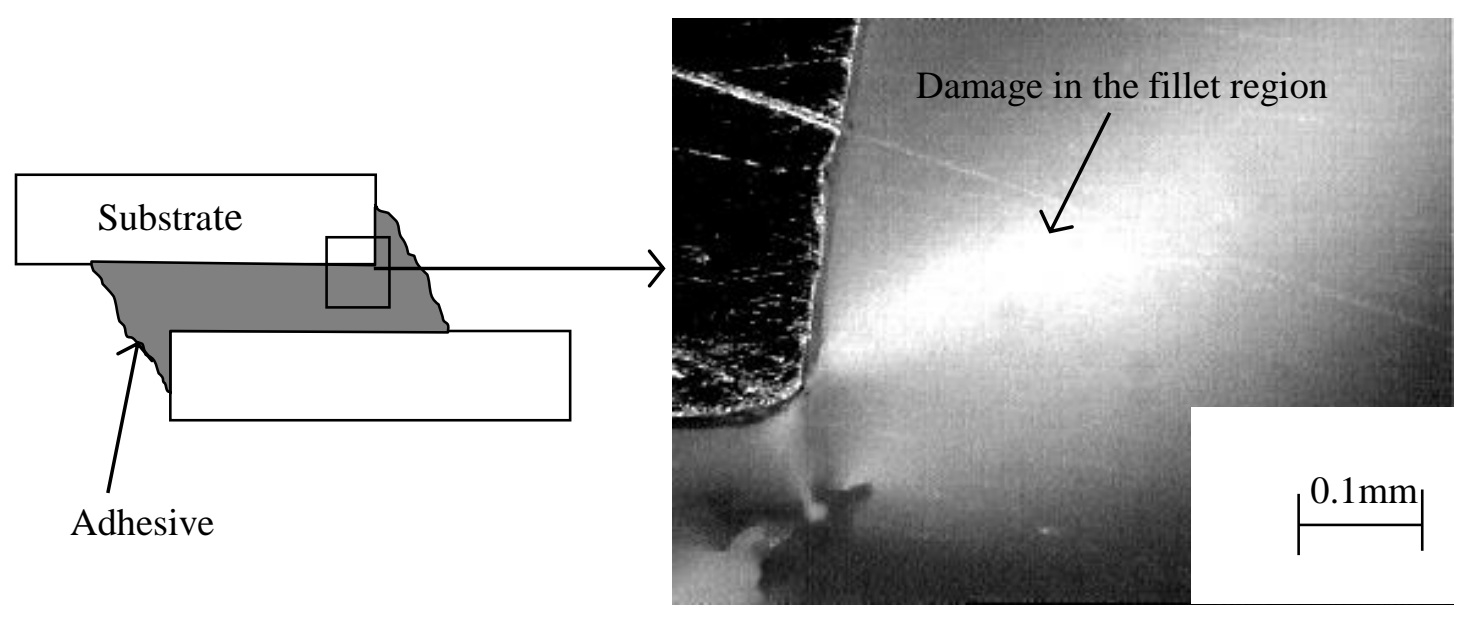

(b)

Fig. 10. Sample tested for 200 cycles (load 63\% of QSFL): (a) BFS plot, (b) micrograph of fillet area in the central section $(\mathrm{C}-\mathrm{C} 1)$ of joint at SG1 end of the overlap. 


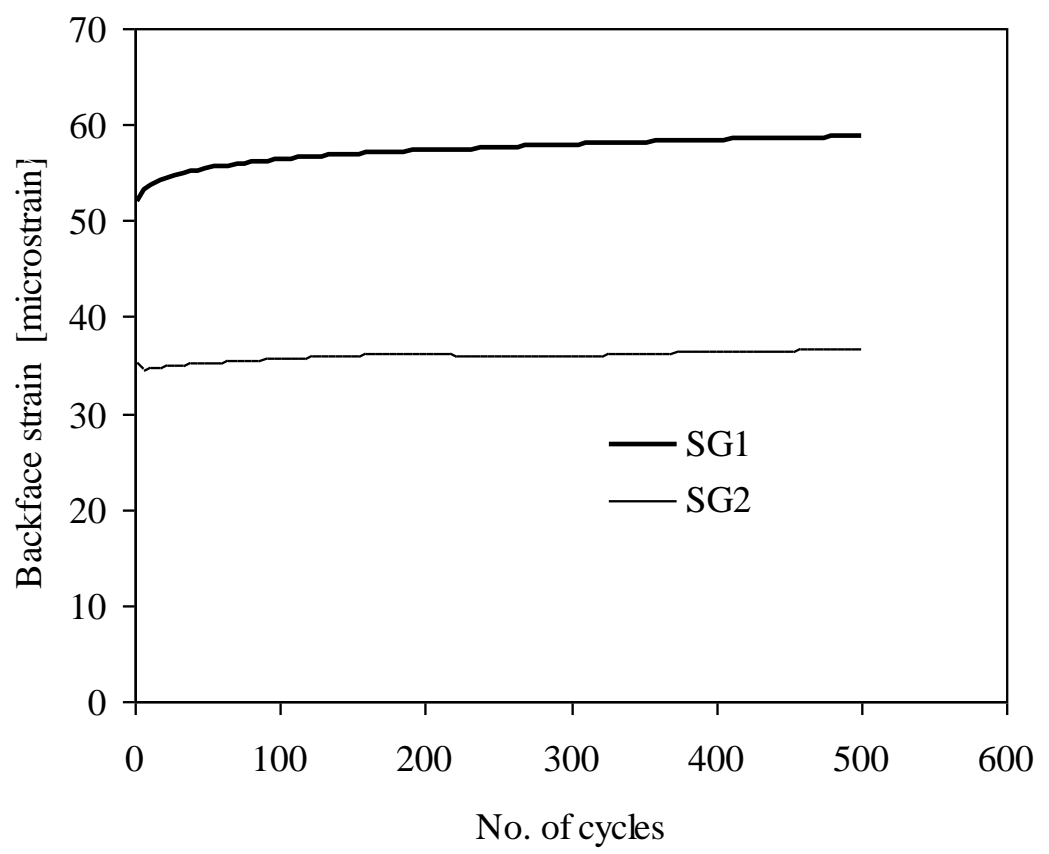

(a)

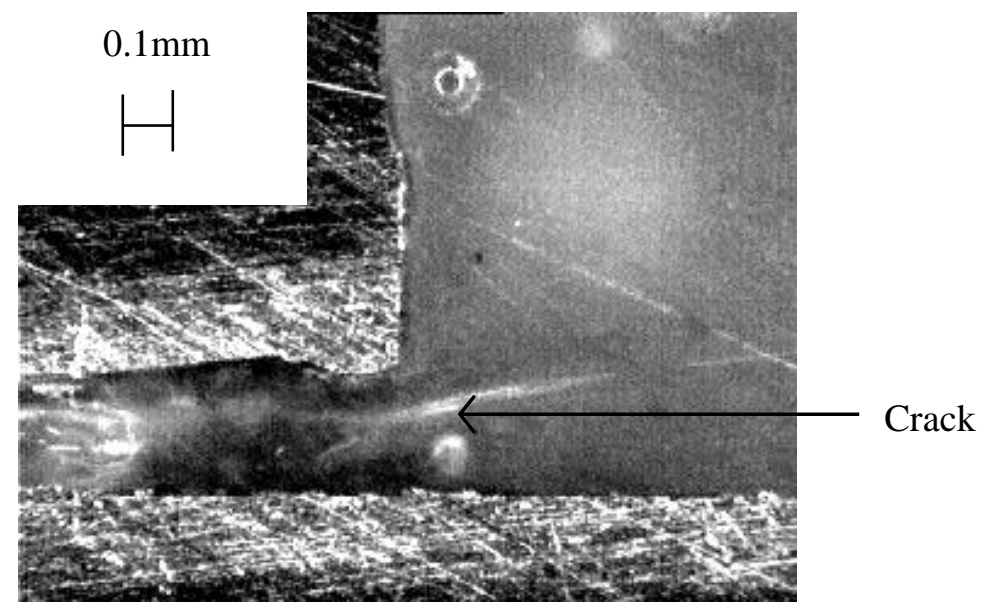

(b)

Fig. 11. Sample tested for 500 cycles (load 63\% of QSFL): (a) BFS plot, (b) micrograph of fillet area in the central section (C-C1) of joint at SG1 end of the overlap. 


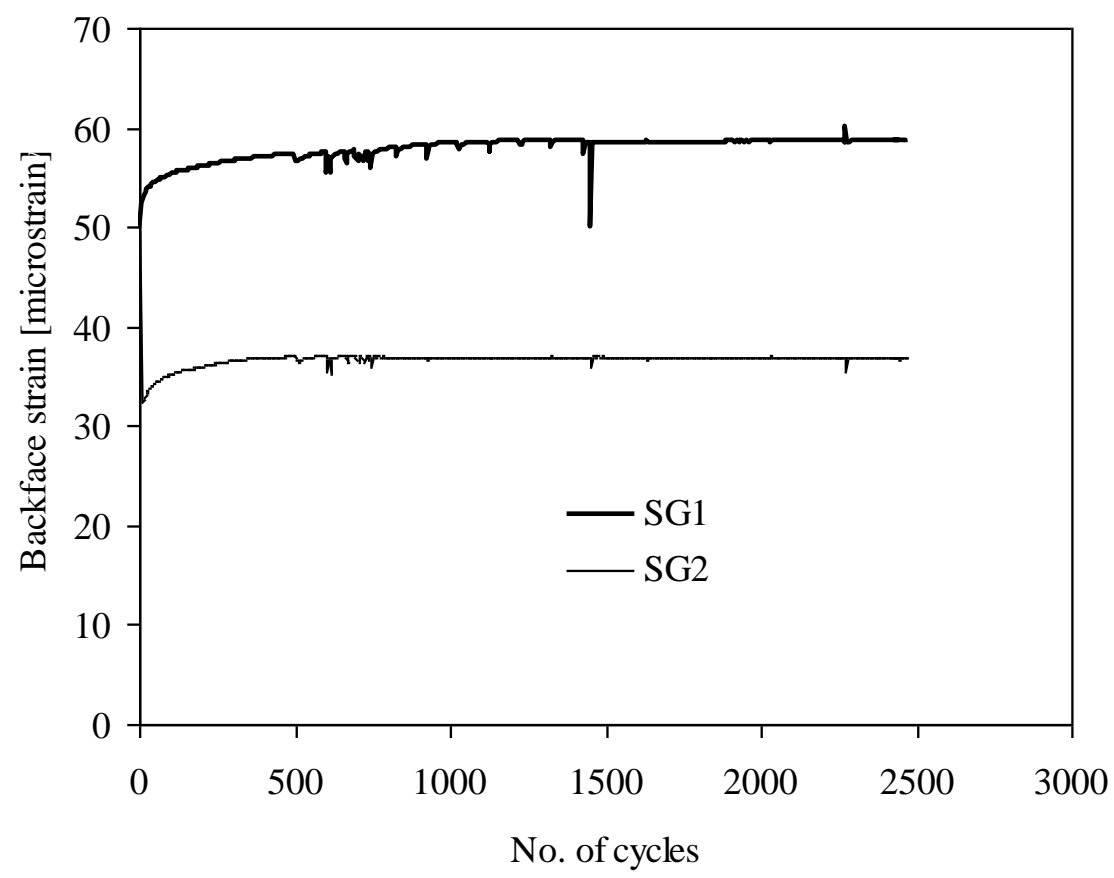

(a)

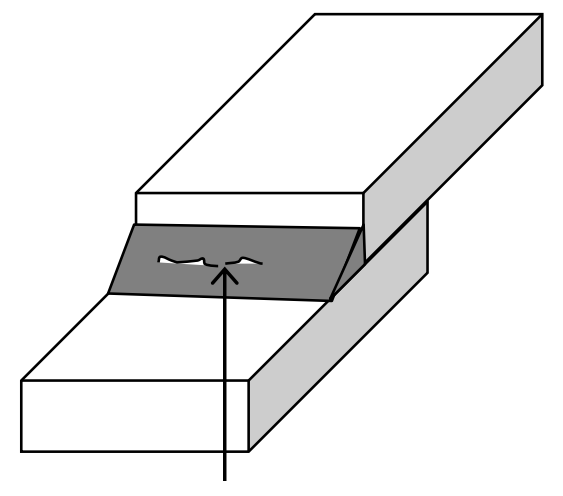

Location of subsurface cracking.

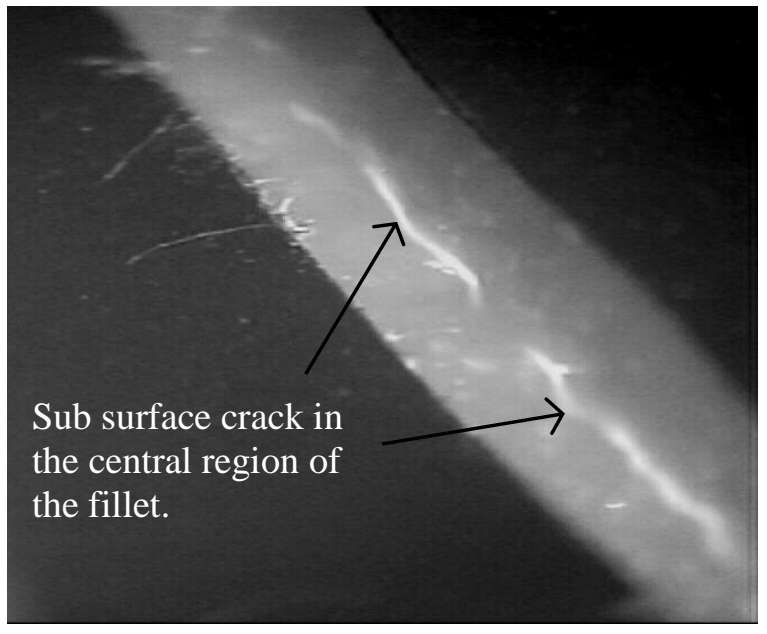

(b) 


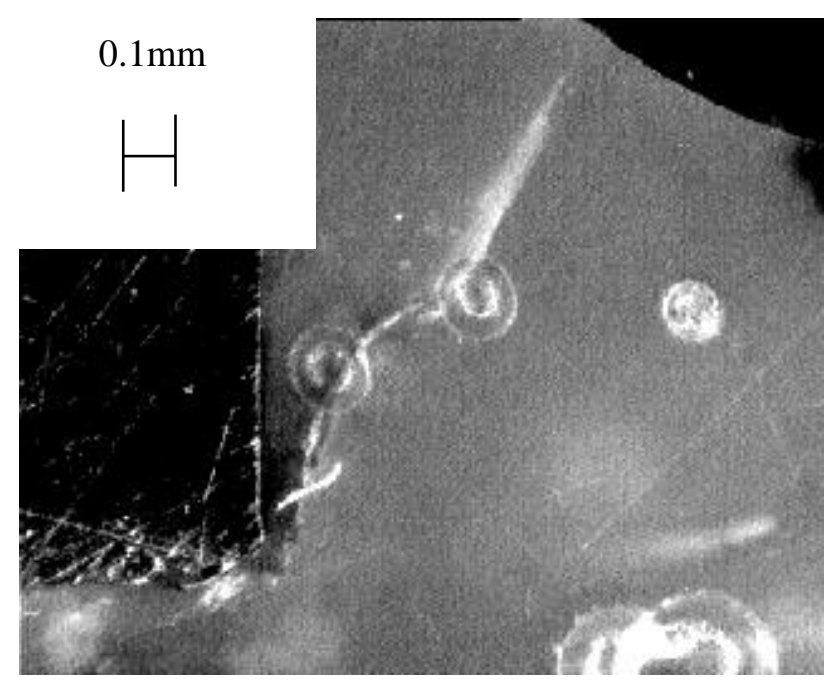

(c)

Fig. 12. Sample tested for 2500 cycles (load 63\% of QSFL): (a) BFS plot, (b) sub surface crack in fillet (SG1 side), (c) micrograph of fillet corner in the central section (C-C1) of joint at SG1 end of the overlap. 


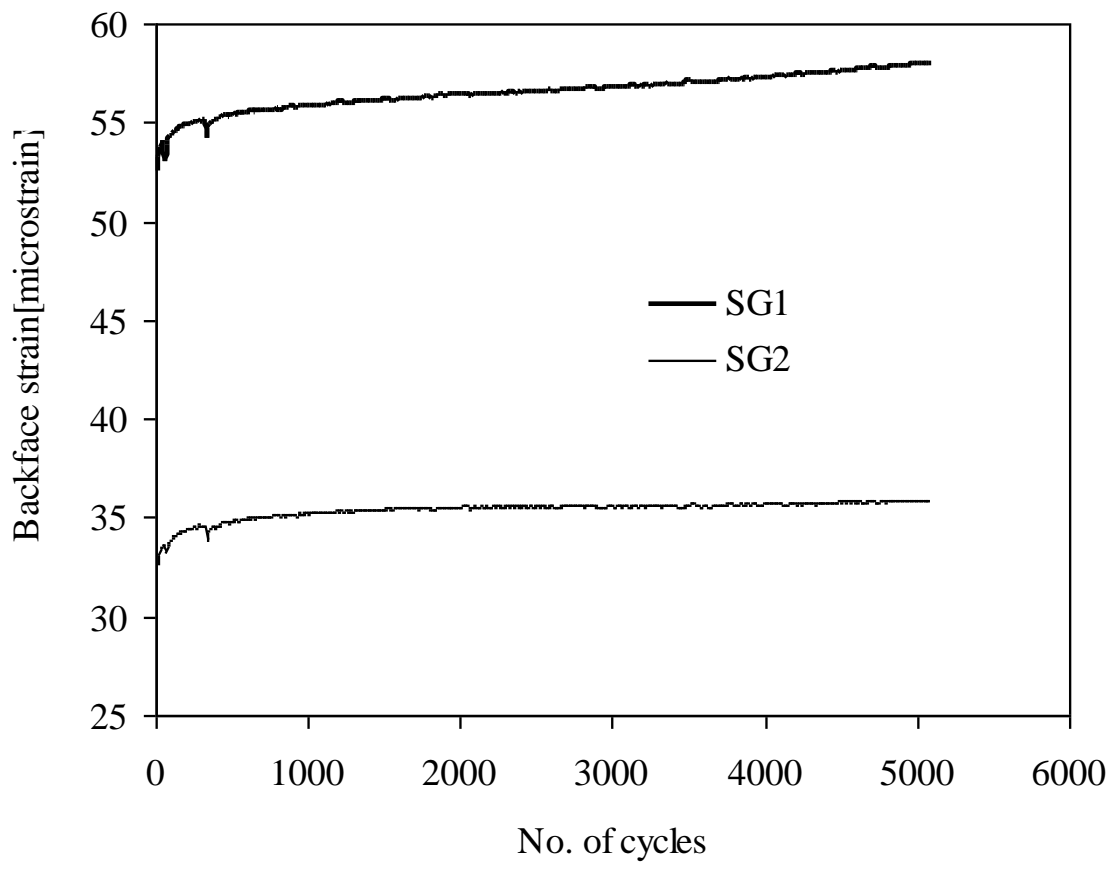

(a)

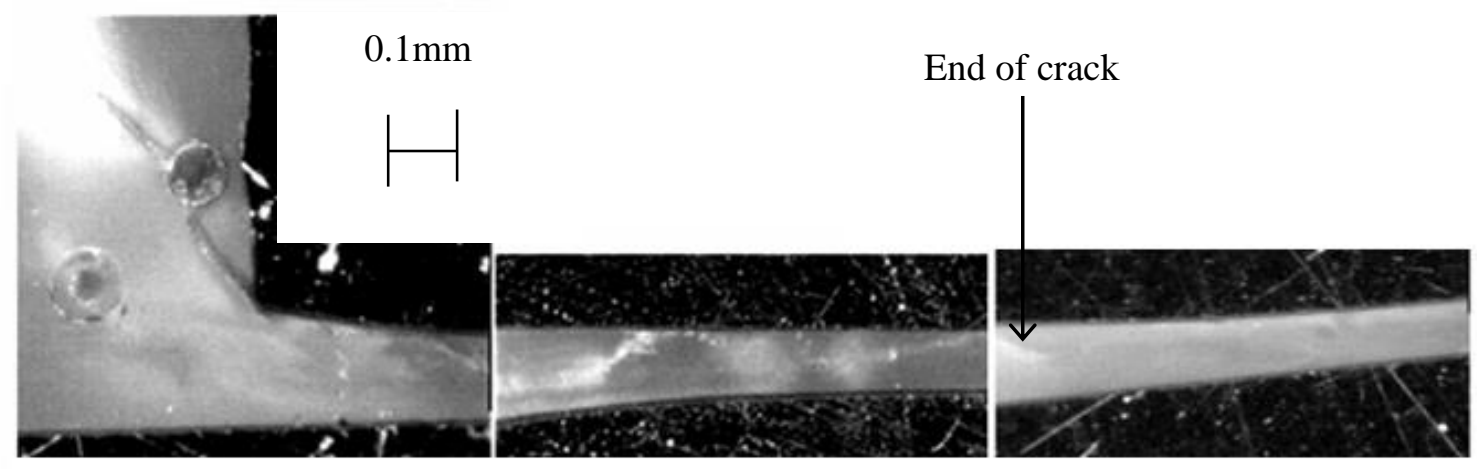

(b)

Fig. 13. Sample tested for 5000 cycles (load 63\% of QSFL): (a) BFS plot, (b) micrograph of fillet and bondline in the central section $(\mathrm{C}-\mathrm{C} 1)$ of joint at SG1 end of the overlap. 


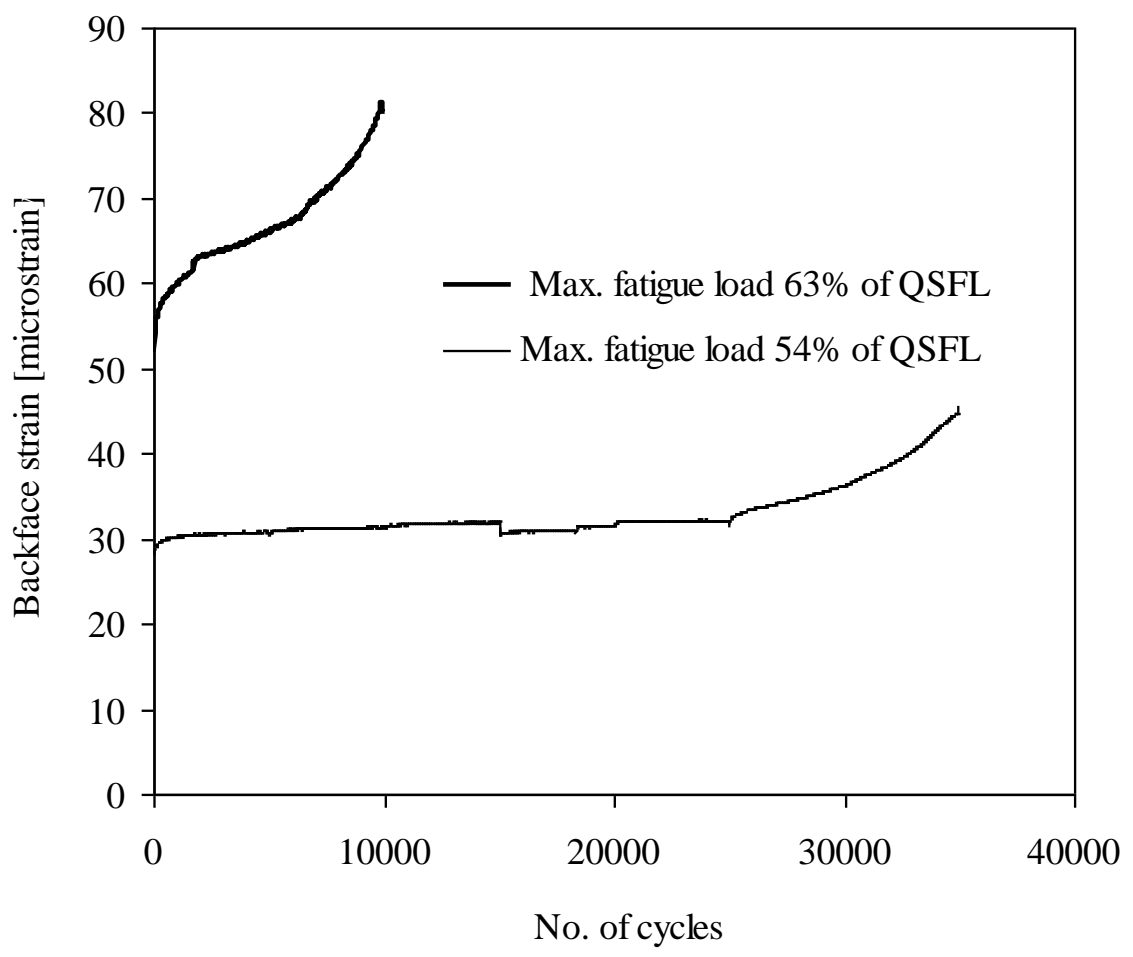

(a)

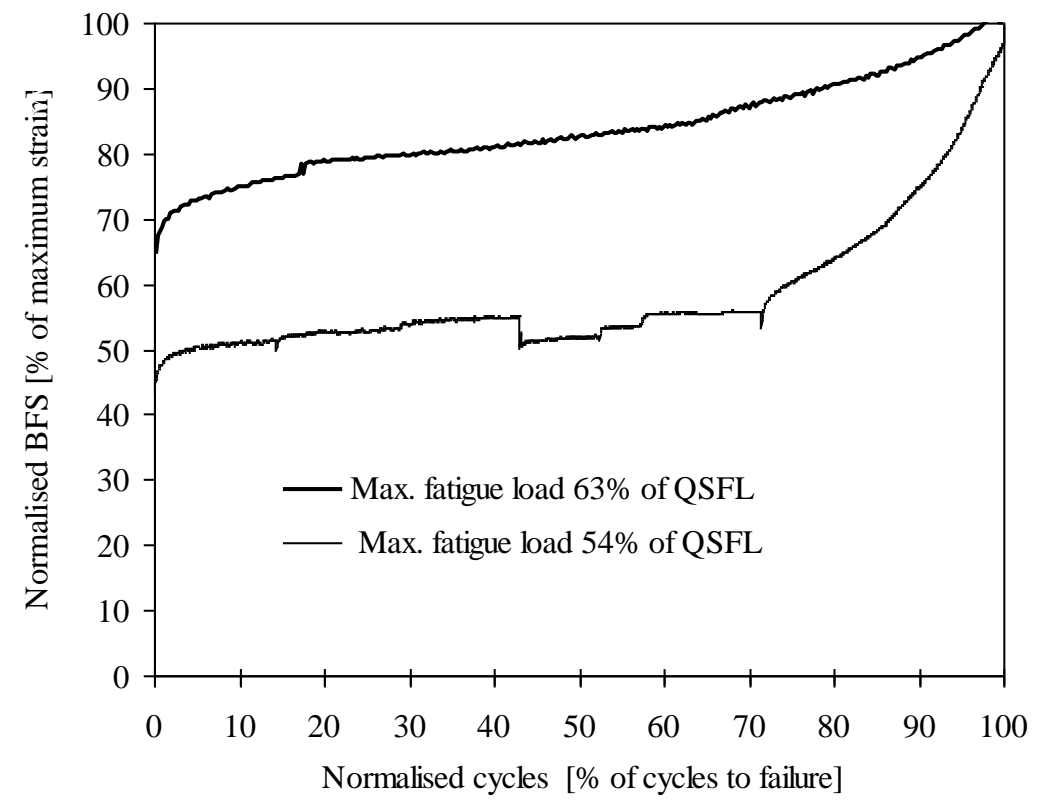

(b)

Fig. 14. (a) Comparison of BFS signal from SG1 for samples tested to failure at different fatigue loads. (b) Comparison of BFS signals using normalised BFS and cycles 


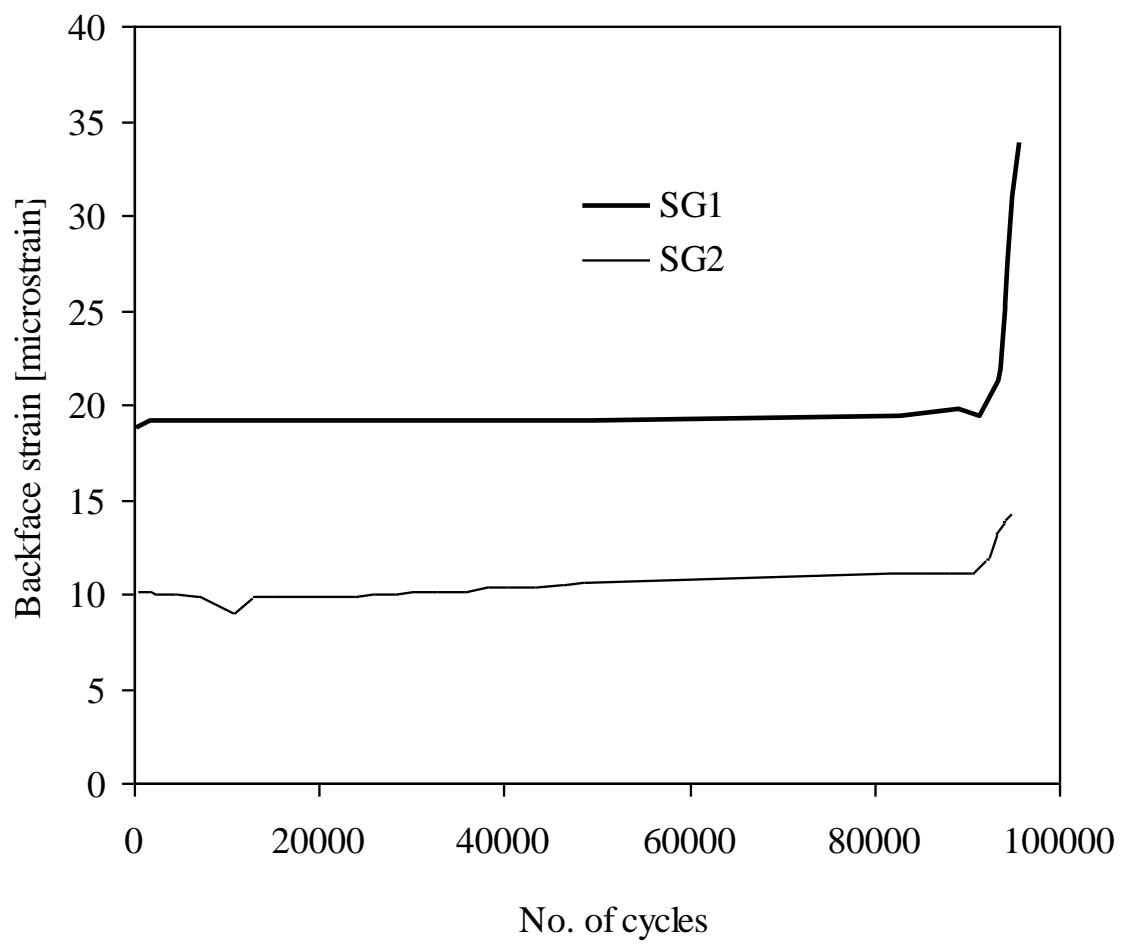

Fig. 15. BFS plot for sample tested to failure (load $40 \%$ of QSFL) 


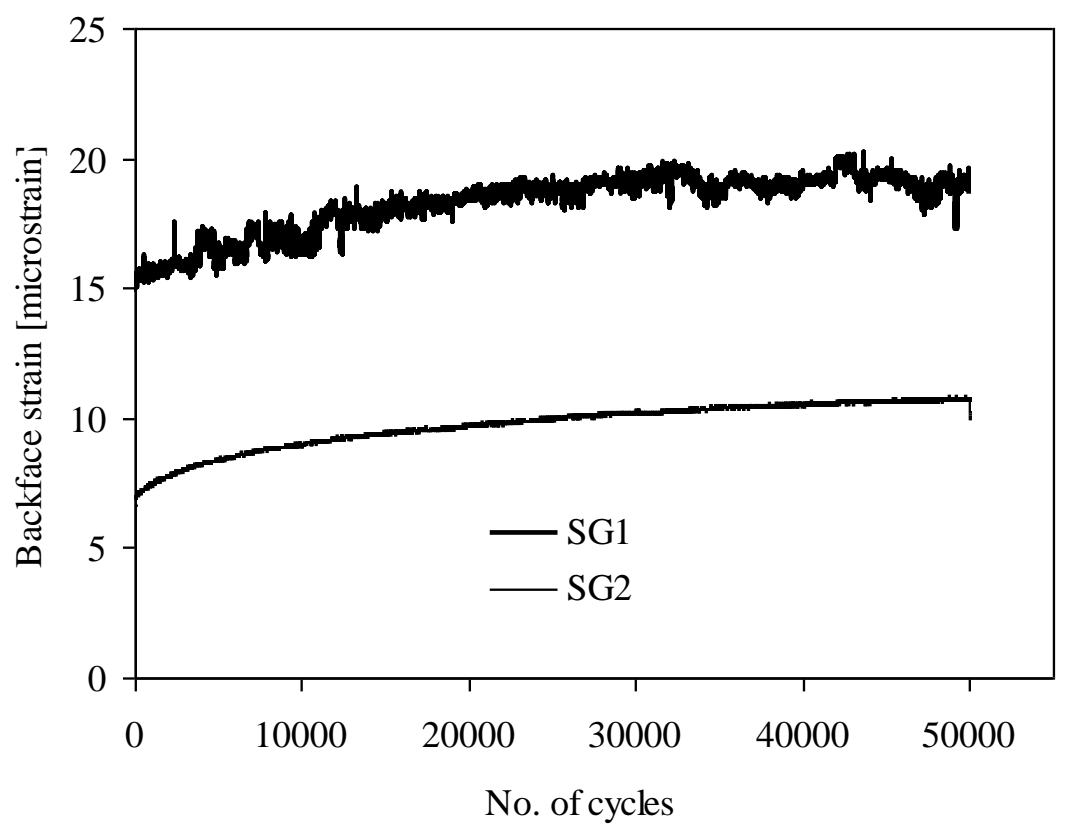

(a)

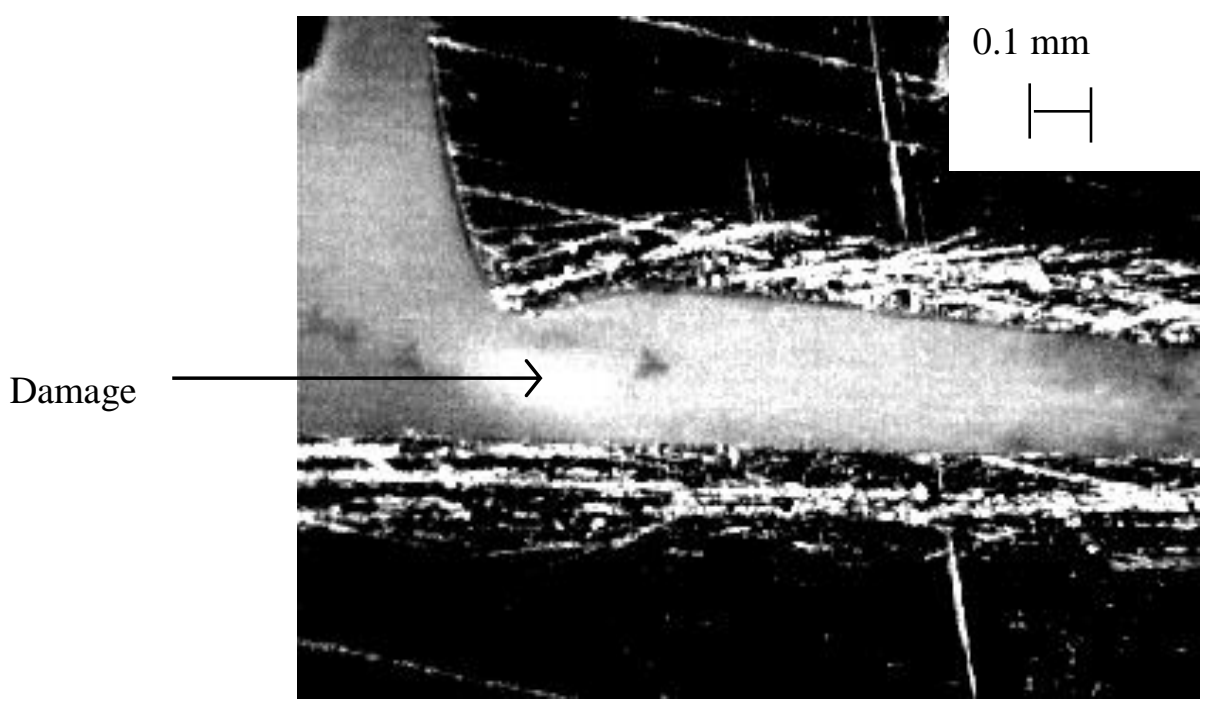

(b)

Fig. 16. Sample tested for 50,000 cycles (load 40\% of QSFL): (a) BFS plot, (b) micrograph of fillet and bondline in the central section (C-C1) of joint at SG1 end of the overlap. 


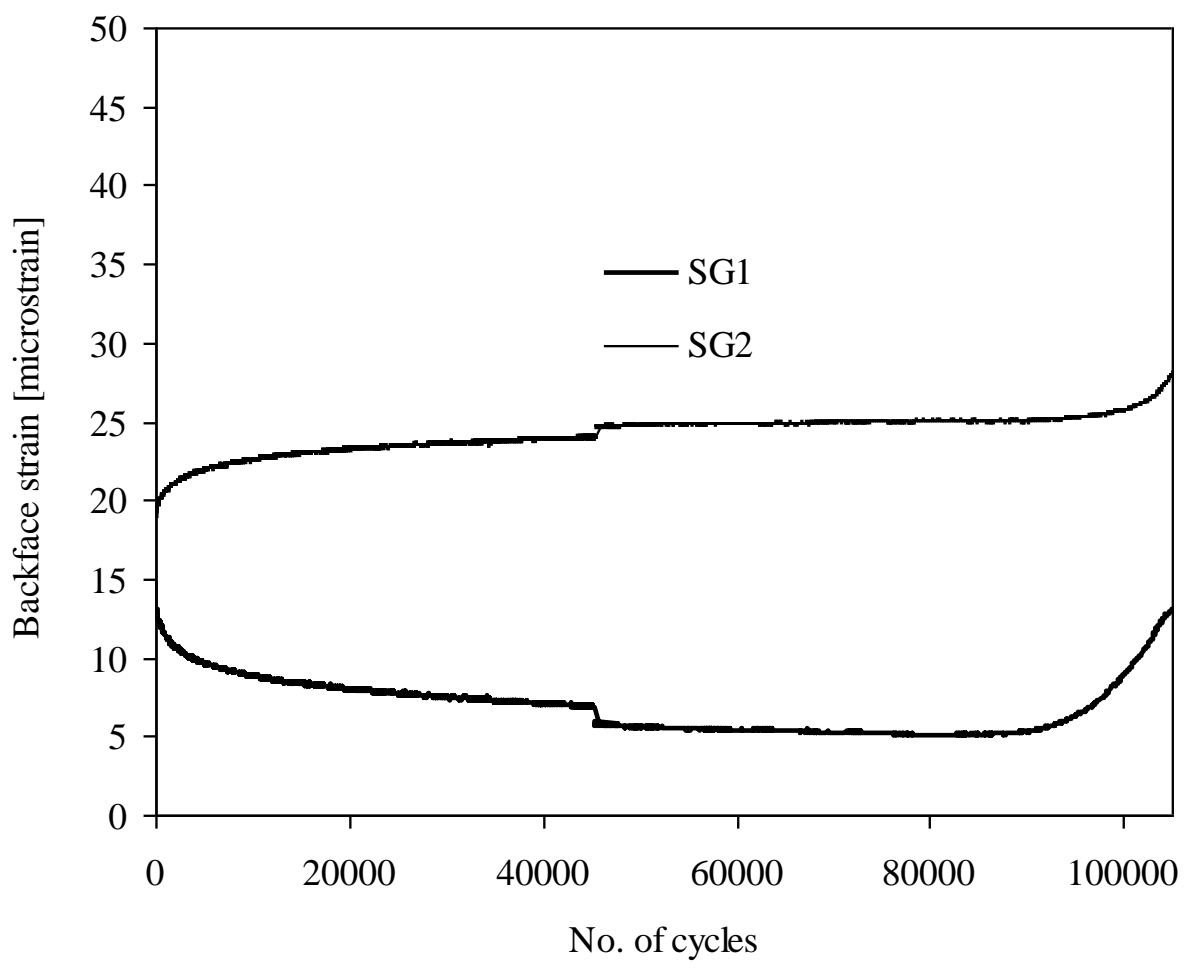

(a)

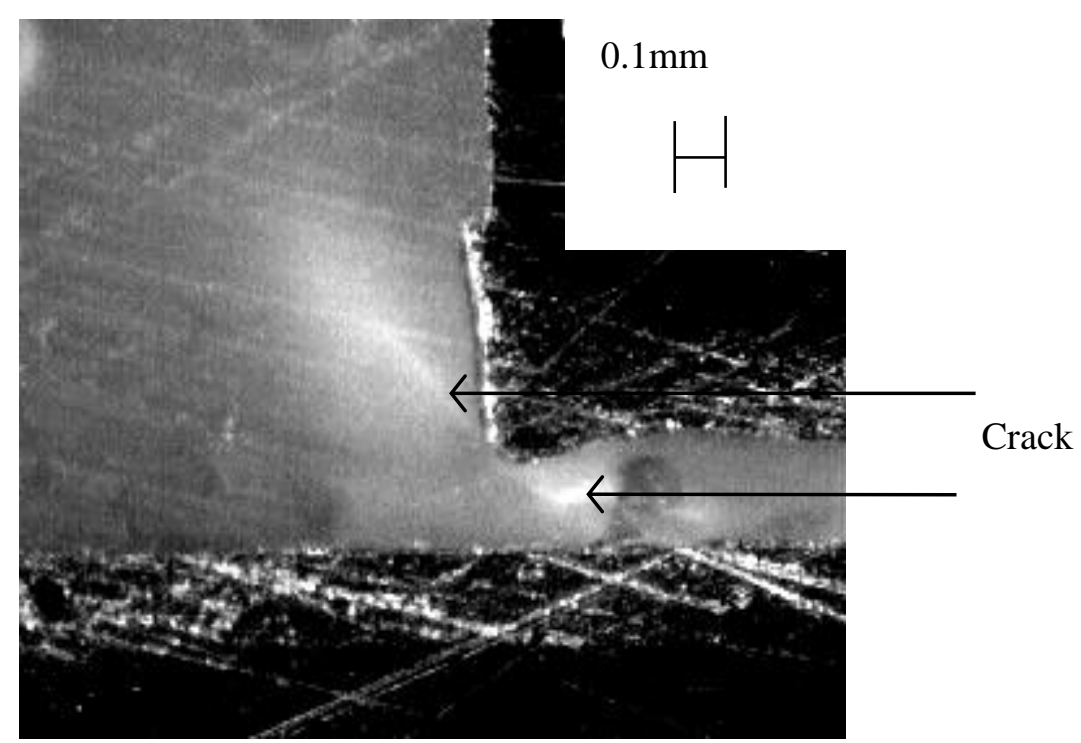

(b) 


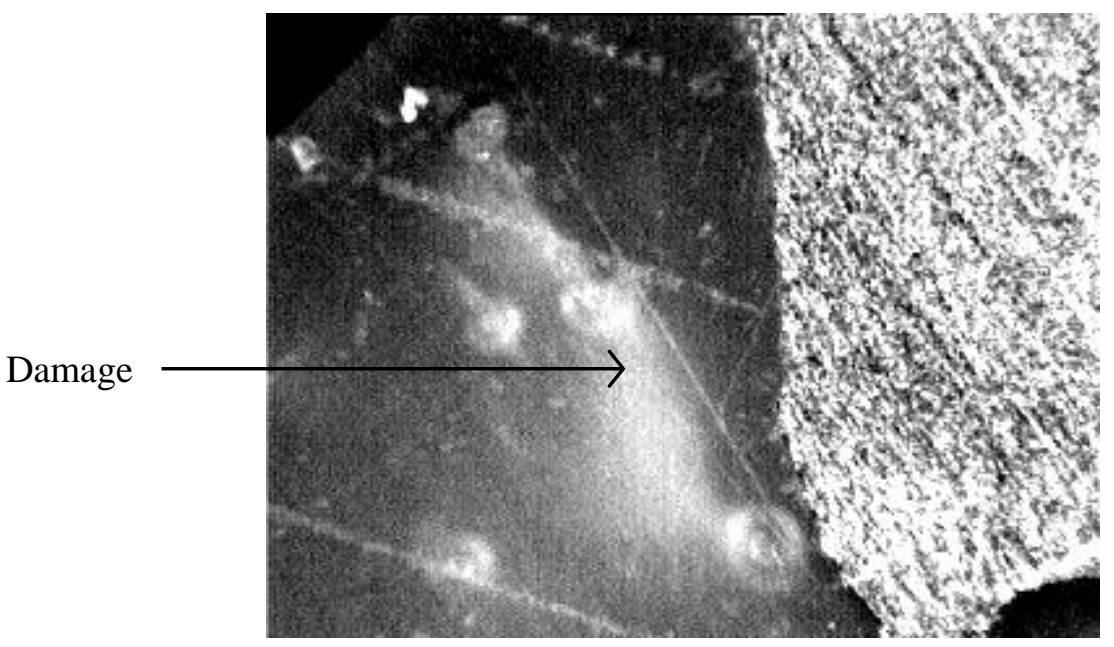

(c)

Fig. 17. Sample tested for 110,000 cycles (load 40\% of QSFL): (a) BFS plot, (b) micrograph of fillet in the central section (C-C1) of joint at SG1 end of the overlap. (c) micrograph of fillet in the left section (L-L1) of joint at SG1 end of the overlap. 


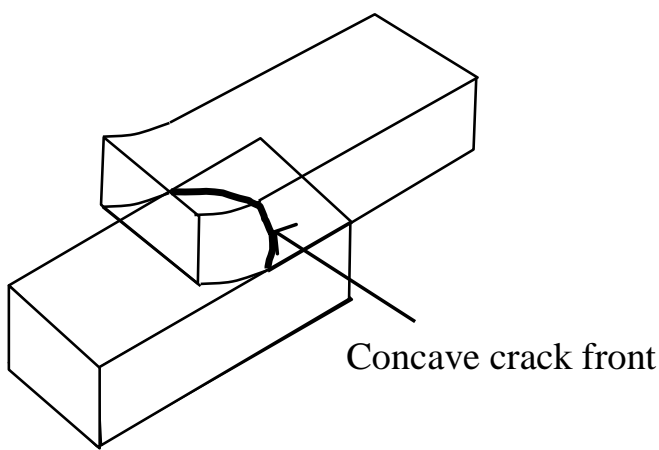

(a)

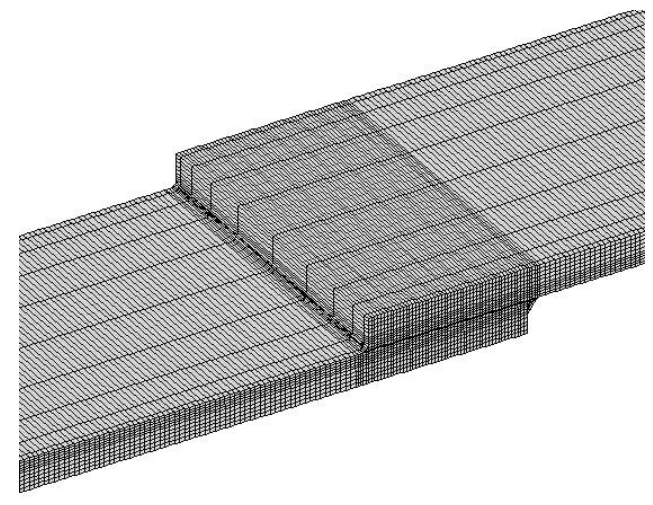

(c)

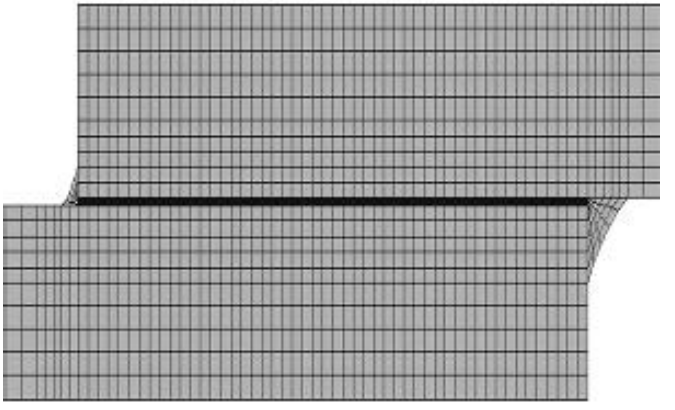

(b)

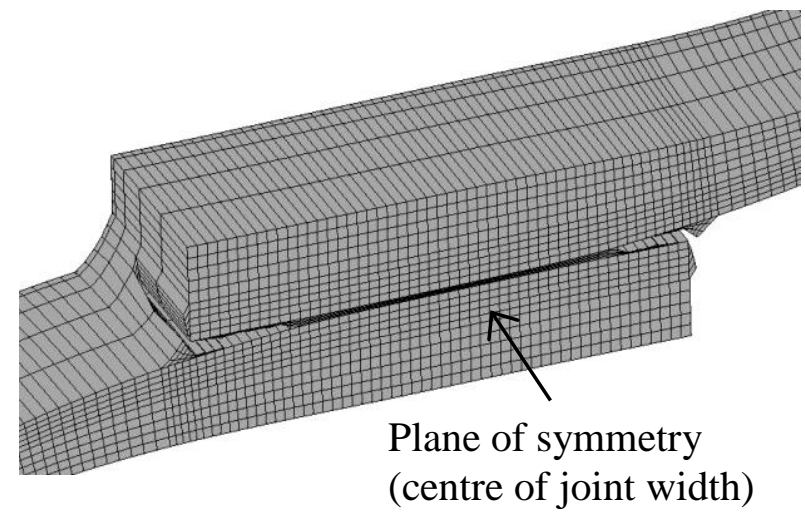

(d)

Fig. 18. (a) Concave crack front shown schematically, (b) 2D view of the finite element model showing different sized fillets, (c) 3D view of the joint (d) deformed mesh with centre crack. 


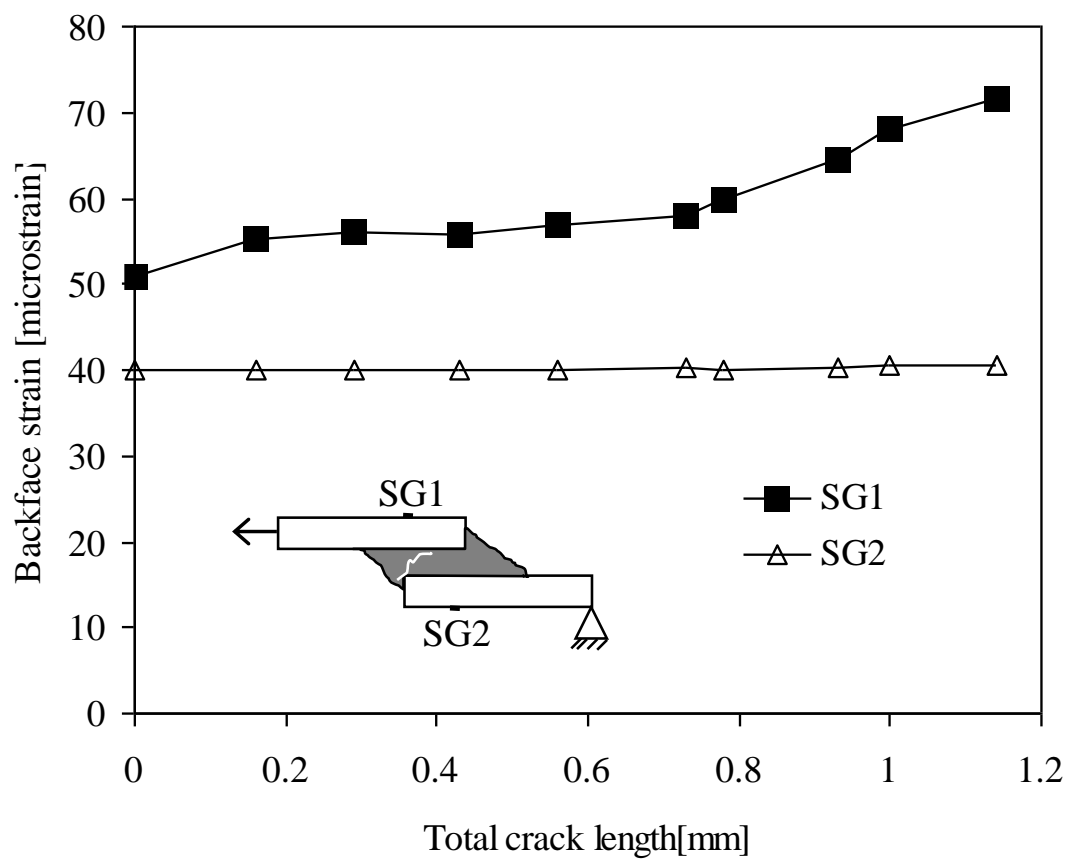

(a)

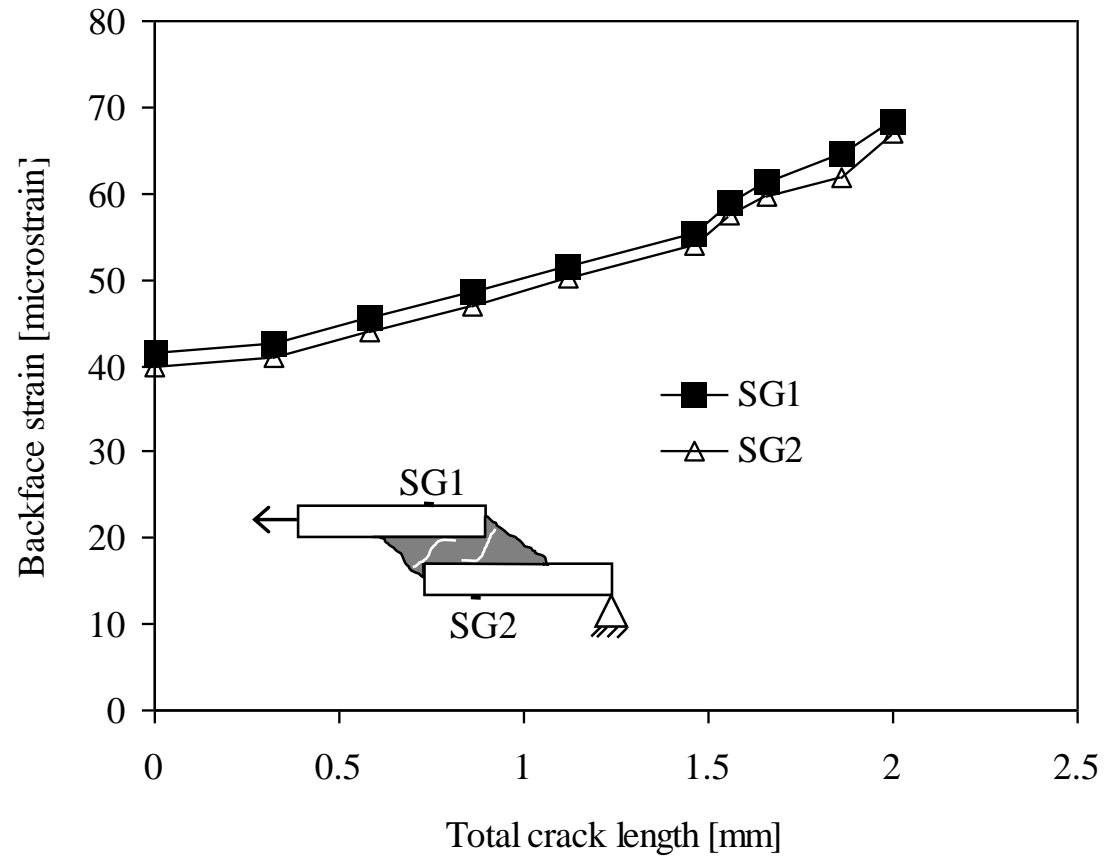

(b) 


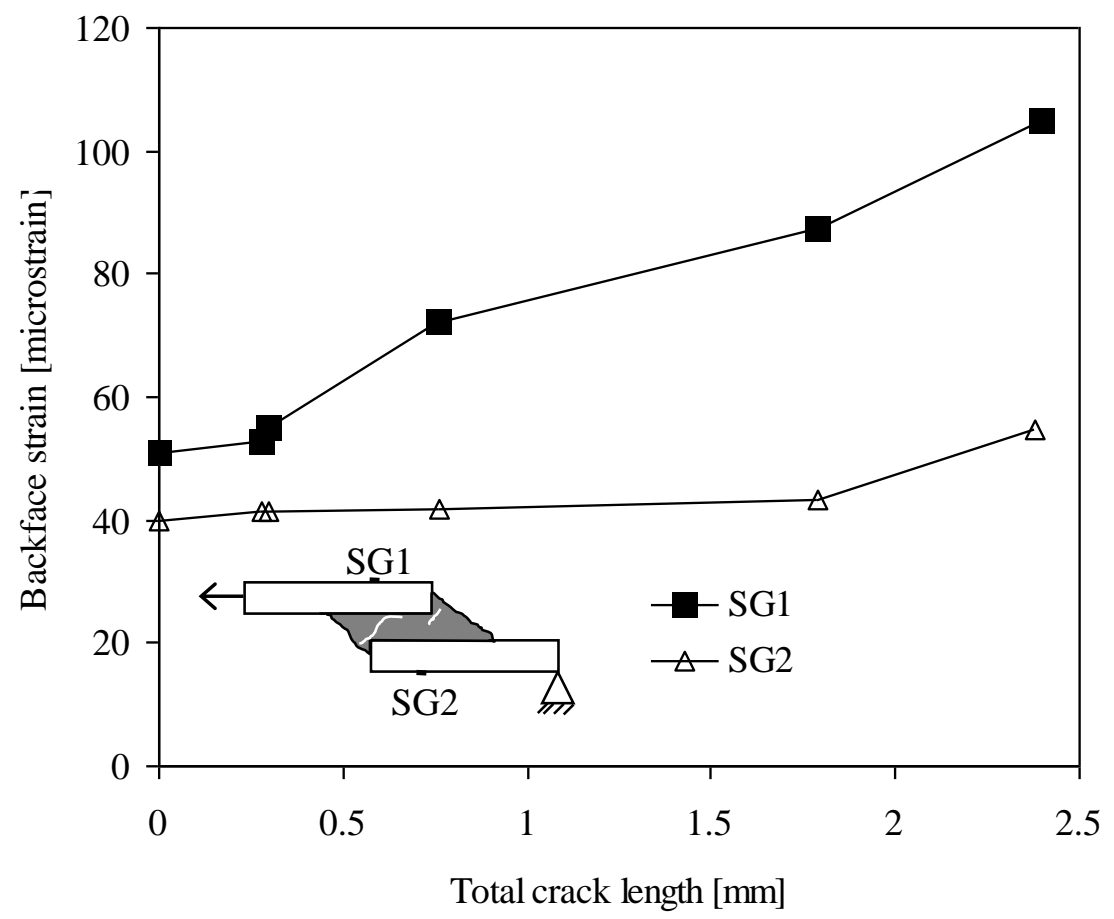

(c)

Fig. 19. FEA simulated BFS plots for (a) type I crack growth, (b) type II crack growth, (c) type III crack growth. 


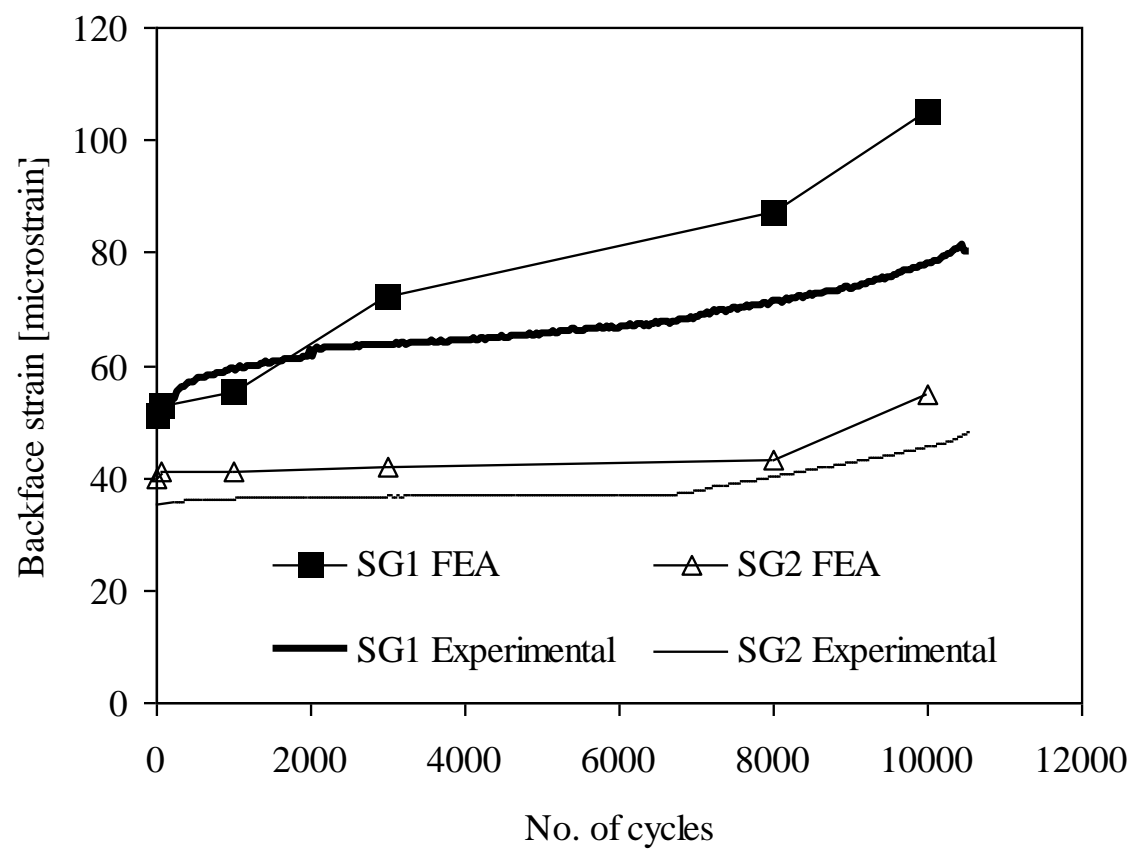

Fig. 20. Comparison of experimental and FEA BFS for type III crack growth. 


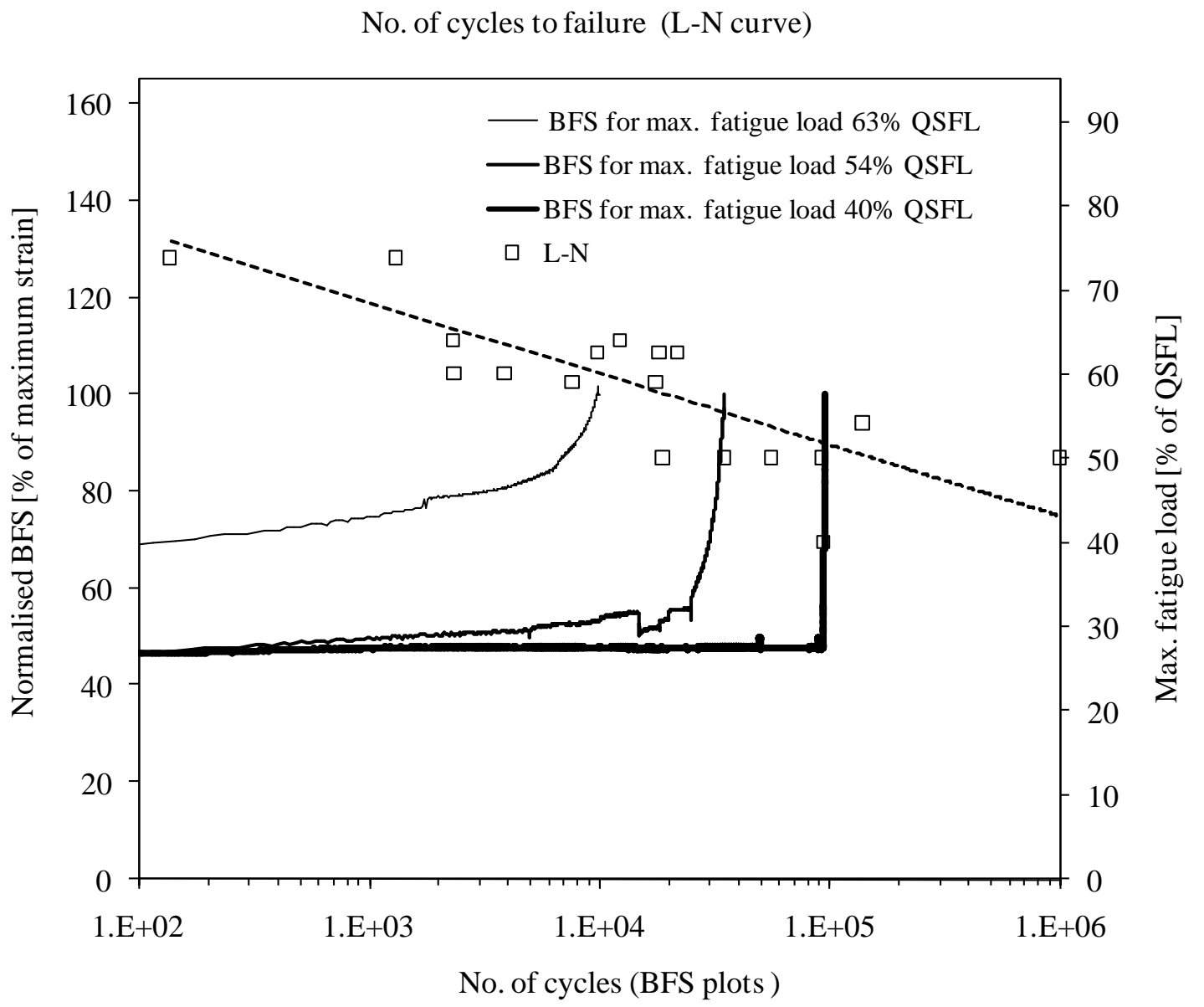

Fig. 21 Normalised BFS and L-N results 


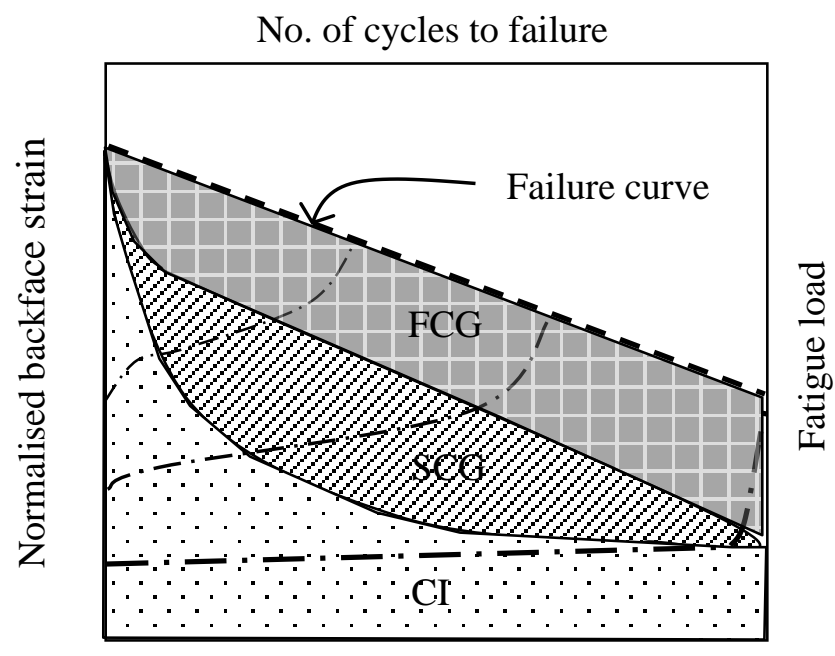

No. of cycles

Fig. 22 Damage progression model 